Florida International University FIU Digital Commons

$11-18-2010$

\title{
Knowledge, behaviors, and beliefs of nannies regarding nutrition for children in their care
}

Melody Garza

Florida International University

DOI: $10.25148 /$ etd.FI15101542

Follow this and additional works at: https://digitalcommons.fiu.edu/etd

Part of the Dietetics and Clinical Nutrition Commons

\section{Recommended Citation}

Garza, Melody, "Knowledge, behaviors, and beliefs of nannies regarding nutrition for children in their care" (2010). FIU Electronic Theses and Dissertations. 3590.

https://digitalcommons.fiu.edu/etd/3590 
FLORIDA INTERNATIONAL UNIVERSITY

Miami, Florida

KNOWLEDGE, BEHAVIORS, AND BELIEFS OF NANNIES REGARDING NUTRITION FOR CHILDREN IN THEIR CARE

\author{
A thesis submitted in partial fulfillment of the \\ requirements for the degree of \\ MASTER OF SCIENCE \\ in \\ DIETETICS AND NUTRITION
}

by

Melody Garza 
To: Interim Dean Michele Ciccazzo

R.Stempel College of Public Health and Social Work

This thesis, written by Melody Garza, and entitled Knowledge, Behaviors, and Beliefs of Nannies Regarding Nutrition for Children in Their Care, having been approved in respect to style and intellectual content, is referred to you for judgment.

We have read this thesis and recommend that it be approved.

Michele Ciccazzo

Barbara Thomlison

Evelyn B. Enrione, Major Professor

Date of Defense: November 18, 2010

The thesis of Melody Garza is approved.

Interim Dean Michele Ciccazzo R.Stempel College of Public Health and Social Work

Interim Dean Kevin O'Shea University Graduate School

Florida International University, 2010 
(C) Copyright 2010 by Melody Garza

All rights reserved. 


\section{DEDICATION}

I dedicate this thesis to my parents Brenda and Hector Garza and Janis Palma, my brothers Eric

M. Garza and Luis Garza, and my boyfriend, Shasmir Coria. Their patience, unwavering support, and most of all love, gave me the strength to complete this thesis. 


\section{ACKNOWLEDGMENTS}

I wish to thank the nannies that participated in my survey, without your participation, this thesis would not have been possible. I would also like to thank the members of my committee, Dr. Michele Ciccazzo and Dr. Barbara Thomlison for their confidence in and dedication to the completion of my thesis. I would also like to thank Holli Thometz for her patience, statistical assistance, and good nature throughout this process.

I am grateful for my family and friends who have supported me in every step of this process. Their undying love and encouragement motivated me not only to complete my degree, but also to complete it with excellence.

Special thanks to Dr. Evelyn Enrione, my major professor, whose gentle yet firm direction in the completion of my thesis was unparalleled and most appreciated. I value her willingness to teach and guide me through the process with patience and commitment. 


\section{ABSTRACT OF THE THESIS \\ KNOWLEDGE, BEHAVIORS, AND BELIEFS OF NANNIES REGARDING NUTRITION \\ FOR CHILDREN IN THEIR CARE}

by

Melody Garza

Florida International University, 2010

Miami, Florida

Professor Evelyn B. Enrione, Major Professor

Nannies impact the development of children; however, research is nonexistent regarding their influence on children's eating habits. The purpose of this study was to examine nannies' nutrition knowledge, feeding behaviors, and beliefs about children and eating. In a descriptive, cross-sectional study, 83 nannies responded to an electronic survey. Respondents were White $(94 \%, n=78)$, females $(100 \%, n=83)$ and full-time employees $(73.2 \%, n=60)$ of one family $(82.1 \%, \mathrm{n}=64)$. Nannies' mean raw score was 24 out of 32 points resulting in $75 \%$ correct in nutrition knowledge. No significant correlations were found between scores and age $(p=.51)$, education $(p=.73)$, or employment years $(p=.47)$. Responses to interaction statements indicated more authoritarian $(35.8 \%, n=24)$ and indulgent $(32.8 \%, n=22)$ feeding styles towards children than authoritative $(14.9 \%, \mathrm{n}=10)$ or uninvolved $(16.4 \%, \mathrm{n}=11)$. Nannies believed that parents/guardians $(66 \%, \mathrm{n}=45)$ had the greatest influence on children's eating habits, however, perceived they had high influence $(79.4 \%, n=54)$. Although nannies exhibited average nutrition knowledge, their authoritarian and indulgent feeding styles may result in poor nutritional habits for the children. While it is important for nannies to attend nutrition education sessions, it is vital for nannies to obtain knowledge on how the various feeding styles affect a child's nutrition. 
II. LITERATURE REVIEW

Nannies and Non-Nutritional Influence $\quad 3$

Childcare Centers and Nutritional Influence $\quad 5$

Childcare Centers and Nutrition Knowledge and Beliefs $\quad 11$

$\begin{array}{ll}\text { Childcare Centers and Feeding Behavior } & 14\end{array}$

Summary of Literature Review 16

$\begin{array}{ll}\text { Conclusion } & 17\end{array}$

$\begin{array}{lr}\text { III. METHODOLOGY } & 18\end{array}$

$\begin{array}{lc}\text { Sample } & 18\end{array}$

$\begin{array}{ll}\text { Instrument } & 18\end{array}$

General Information and Demographic Section $\quad 19$

$\begin{array}{ll}\text { Nutrition Knowledge Section } & 20\end{array}$

$\begin{array}{lr}\text { Nutrition Behavior and Beliefs Sections } & 22\end{array}$

$\begin{array}{ll}\text { Expert Panel } & 24\end{array}$

$\begin{array}{ll}\text { Pilot Study } & 24\end{array}$

$\begin{array}{ll}\text { Procedures } & 25\end{array}$

$\begin{array}{lr}\text { Statistical Analyses } & 25\end{array}$

$\begin{array}{lr}\text { IV. RESULTS } & 27\end{array}$

$\begin{array}{ll}\text { Demographics } & 27\end{array}$

$\begin{array}{lr}\text { Nutrition Knowledge } & 28\end{array}$

$\begin{array}{lr}\text { Nutrition Behaviors } & 29\end{array}$

$\begin{array}{ll}\text { Food and Snacks } & 29\end{array}$

Feeding Styles $\quad 29$

Beliefs - Nutritional Influence on Children 31

V. DISCUSSION $\quad 32$

Demographics $\quad 32$

Nutrition Knowledge $\quad 34$

$\begin{array}{ll}\text { Nutrition Behaviors } & 36\end{array}$

Food and Snacks $\quad 36$

Feeding Styles $\quad 36$

Beliefs - Nutritional Influence on Children $\quad 38$

$\begin{array}{ll}\text { Research Questions } & 39\end{array}$

$\begin{array}{ll}\text { Limitations } & 39\end{array}$

Recommendations $\quad 41$

Future Research

$\begin{array}{ll}\text { Conclusion } & 41\end{array}$

LIST OF REFERENCES

$\begin{array}{lr}\text { APPENDICES } & 59\end{array}$ 


\section{LIST OF TABLES}

\section{TABLE}

Table 1. Demographic characteristics of respondents who completed a national survey: Knowledge, behaviors, and beliefs of nannies on nutrition and children

Table 2. Sources of nutrition information that nannies access

Table 3. Total points of nutrition knowledge scores

Table 4. Nanny responses when asked to classify item as food or nutrient

Table 5. Nanny responses when asked to identify the correct pairs of food and nutrient

Table 6. Nanny responses to the question: A kilocalorie (calorie) is a measure of?

Table 7. Nanny responses when asked to identify the TRUE statement

Table 8 . Nanny responses when asked to identify which practices

make food safe

Table 9. Nanny responses when asked to describe the frequency of behaviors when eating

Table 10. Nanny responses to feeding behaviors characterized by quotes

Table 11 . Nanny responses to feeding behaviors characterized by statements

Table 12. Nanny responses when asked to describe their level of influence

Table 13. Nanny responses when asked to rate the level of importance 


\section{LIST OF FIGURES}

FIGURE

PAGE

Figure 1. The last nutrition workshop, class, lecture, and/or information session attended by the nannies

Figure 2. Yes or no belief questions answered by the nannies

Figure 3. Nanny responses to the question, "Who shops for the food and/or snacks that the children you care for eat?"

Figure 4. Nanny responses to the question, "Who decides what food and/or snack choices the children have to eat?

Figure 5. Nanny responses to the statement, "The person(s) who has/have the greatest influence on eating habits of the children you care for is/are:" 


\section{INTRODUCTION}

It is well known that relatives, guardians and peers who spend the majority of time with

children greatly influence childhood eating patterns and attitudes towards healthy eating $(1,2,3,4)$. However, information is lacking regarding the impact of non-relatives on the eating habits of children.

The escalation of mothers participating in the labor force is commonly regarded as the most significant factor fueling the increased demand for childcare services $(3,5,7)$. In 2009 , the percentage of mothers with children under six years old in the United States labor force was $64.2 \%$, while those whose youngest child was six to 17 years old was $77.3 \%(6)$. With the increasing number of women entering the workforce and laws mandating mothers who are on welfare be employed, a greater number of households will demand childcare assistance $(5,7)$. According to the Bureau of Labor Statistics, childcare workers hold approximately 1.3 million jobs in the United States with $19 \%$ of these employees situated in private households (8). It is projected that by the year 2018 , there will be an $11 \%$ increase in all genres of childcare workers as the role of parents and relatives in caregiving continues to decline (8).

Studies on the nutritional influences of in-home, non-related caregivers, specifically nannies, in relation to the children they care for are non-existent. Most studies examine the feeding roles and nutritional influences of non-parental caregivers in state-licensed childcare centers (11-16). These studies cannot be generalized to the nannies because nannies are not registered through state licensing offices, nor are they employed by childcare centers (9). They are private household employees who are commonly hired to care for children from birth to the age of twelve (8). While these workers often perform daily household chores, nannies are required to tend to the child's development including "early education, nutrition, health, and other needs (8)." With these responsibilities, it is evident that the nannies' decisions about food and eating can alter the nutritional quality of a child's food intake. Since these decisions can influence 
the overall health status of children, research is warranted in this area of childcare. Additionally, considering that 35 million children rely on in-home childcare, research is necessary to examine the understanding that in-home caregivers, specifically nannies, have regarding nutrition and feeding (9). Therefore, the purpose of this study is to examine the nutrition knowledge and feeding behaviors of nannies as well as investigate whether nannies believe they influence the child's eating habits.

Research Questions:

What is the average nutrition knowledge score obtained by the nannies?

Are nannies' feeding behaviors authoritarian, authoritative, indulgent, or uninvolved?

Do nannies believe they have a nutritional influence on the children in their care? 


\section{LITERATURE REVIEW}

Research in the area of feeding and nutrition among children may be found in an array of disciplines. As such, a variety of databases were searched under the subjects of early education, medicine, social sciences, public health, and social work including, but not limited to, CINAHL, Medline, Pubmed, ERIC, and PsycINFO. Various combinations of the following terms were typed into the search box: applied: child care/childcare; child care/childcare providers; child care/childcare workers, nanny/nannies; in-home child care/childcare; private child care/childcare; nutrition knowledge and child care/childcare; feeding styles and behaviors; influence in child care/childcare.

Information on the feeding, diet, and/or nutrition relationship between nannies and the children in their care were not found. The search did yield one study from South Africa that investigated the racial influence a nanny has on children (10). Investigations amongst children and non-parental, non-related caregivers have been completed with childcare workers in licensed childcare centers. Peer-reviewed articles reported nutritional influence, nutrition knowledge, and feeding styles and behaviors of employees in licensed childcare centers. Therefore, those studies are reviewed. Five studies were conducted in the United States (US) and one in the United Kingdom (UK).

\section{Nannies and Non-Nutritional Influence}

According to South African researchers in a 1975 study, many families, both "white and brown," in South Africa employed nannies, usually of the Black race (10). The researchers hypothesized that due to the close association between nanny and child, the children who spend long periods of time, noted as one year or longer, with Black nannies would have a more favorable attitude towards Blacks than would children who rely on Black nannies for a short duration of less than a year. 
To study the color concepts attitudes of the children, a biographical questionnaire was developed and given to the parents of the children. The questionnaire not only consisted of the child's name, age, and sex, but questions such as the parents' occupational and educational status, information on whether the nanny was employed for the child, the type of caregiving the nanny was employed for, the duration of the nanny's employment, and the parental impressions about the nanny-child relationship. In addition to the questionnaire, the researchers used an Animal Picture Series (APS) to assess the connotative meanings of the colors black and white and a Human Picture Series (HPS) to observe the attitudes toward dark skinned and light skinned persons. The APS consisted of nine cards: six cards of two identical animals where one was white and one was black and 3 "filler" cards of objects in colors other than black and white. The HPS consisted of nine cards: eight full length drawings of two same-sex children depicted in either solitary play, running, jumping, sitting, standing, eating, reading, walking, or bending. The two children in the drawing only differed in hair and skin color where one was regarded as a White and the other as Black. Four cards showed boys and four cards showed girls. The ninth card was a green and yellow filler card.

Selected from a local nursery, 65 pre-school Indian children returned the biographical questionnaire in which 40 were selected (10). The children were between the ages of three and five years old, from middle and upper class homes, and had Black nannies. Children were then separated in two groups: those who had the same nanny for over a year and those with the nanny for less than a year. From there, the groups were further divided on whether the APS or HPS was presented first. The final population consisted of four groups totaling 23 females and 17 males with an average age of four years nine months old (10).

Each child was tested two times with a period of one to three days between tests. The APS and the HPS were used in similar manners, where the children were asked to describe the picture series using adjectives and story-telling (10). Six positive adjectives 'good, clean, clever, 
pretty, nice, helpful' and six negative adjectives 'lazy, stupid, dirty, ugly, bad, naughty' were utilized (10). While both groups display a negative color concept attitude towards Blacks and the majority of the subjects believe that Black nannies are dominantly 'bad, ugly, lazy, stupid', yet 'helpful,' results indicated that children under the care of Black nannies over long periods have a more positive attitude towards Blacks than those who have been under a nanny's care for a short duration (10). Although minimal, care provided by Black nannies proved to ease negative cultural bias towards Black figures. However, the researchers speculated that the minimal effect was due to conflicting messages brought forth to children by positive personal experiences with Black nannies and negative attitudes of parents, peers, and politics (10). Although food or nutrition was not the focus of this study, it is imperative to note the influence nannies have over children.

\section{Childcare Centers and Nutritional Influence}

Briley et al conducted a study to examine how foods and snacks consumed before and after a child's time at a childcare center complemented the meals the caregivers served at the facility (11). The basis of the study was not only to observe if children were meeting their nutritional needs, but to explore the suggestion that parents believe childcare is equally or more important than home for influencing food preferences.

Based on the review of a mail-in survey and menus of 101 childcare centers, 12 nonprofit childcare centers in central Texas were selected to participate in the study. Six centers had a menu that provided at least $50 \%$ of the Recommended Daily Allowances (RDA) for energy and nutrients and six centers incorporated menus that fell substantially below the RDAs. Additionally, each center's director chose five families from the facility to participate in the study of what the children were eating outside their time in childcare. Registered Dietitians were responsible for explaining the study, teaching the families how to measure and record the food intake of the child, collecting copies of each facility's menu, and observing the food service and children's intake for three consecutive days at the center. During the same three-day period, the parents of 
the participating families were asked to submit a food record indicating the foods the child ate before and after the hours the child spent at the center. Food records were collected for 51 children between the ages of three and six.

The researchers calculated nutrient intakes with the Professional Nutrient Calculator (PNC, version 2.2, 1996, Austin, Tex). Intakes were then compared to the recommendations set by the American Dietetic Association (ADA) who suggest that children who spend eight hours or more in a childcare center should receive one-third to half of their daily intake before and after attendance at the childcare center and half to two-thirds from the facility. Results indicated that foods provided to children before and after their time at the center almost always contributed to as much or more than the recommended $33 \%-50 \%$ share of a full-day's requirement for all nutrients apart from calcium, iron, and zinc During time spent at the childcare center, children consumed $50 \%-67 \%$ of the recommended share for all nutrients, except niacin, iron, zinc, and total energy intake (11). A 24-hour record of the children's total intake was inverted when compared to the United States Department of Agriculture (USDA) Food Guide Pyramid. Fats, oils, and sweets were the foundation of the pyramid while grains formed the peak. However, the results indicated that when children were at the facilities, they ate a substantially less amount of fats, oils, and sweets as compared to the time the children spent away from the center. It was speculated, that the increased amounts of fats, oils, and sweets provided outside of childcare center was due to the overall low energy intake of the children while in the childcare center. The researchers suggested that low energy intake may have caused hunger and irritability, and upon leaving the facility, parents may have relied on convenient, unhealthy foods to alleviate a child's lack of food and petulance. The lesson the children may have learned from these reoccurring food habits is that during time with the family, when there is freedom of choice about what to eat, the food preferences may be those of fast, high fat, high sodium foods. The long term nutritional concern indicated with this finding is that members of a family may model and reinforce harmful and 
unhealthy food habits. Additionally, results showed that parents and caretakers believed that the other was responsible for influencing, arranging, and implementing the nutritious components of the child's diet. The researchers speculated that with the various foods served in and out of the center, the children were confused as to the proper healthy eating habits.

This study identified a need for education and training that targeted both parents and employees of childcare centers to work together and discourage children from eating unhealthy foods, especially during their time away from the facility. Additionally, the researchers indicated the menu as an appropriate target for concentrated efforts in increasing nutrients such as iron and zinc in a child's diet. Due to a more intimate setting and increased interaction between in-home caregivers and parents, similar education and training may be warranted for this population of childcare employees.

In the UK, a similar study was conducted (12). Moore et al investigated the food offered by childcare providers as well as the providers' attitudes toward their role in nutritious eating. A questionnaire was developed to investigate the kinds of foods provided and the attitudes of the caregivers regarding their role in promoting healthy eating (12). A random sample of 345 childcare providers were drawn from West Yorkshire and selected based on type of provider; Local Authority (LA) nursery, private nursery, or registered child-minder. LA nurseries are funded by the LA and governed by their policies and private nurseries are operated as independent businesses. Child-minders are defined as those who provide childcare in a home environment (12).

Additionally, 25 face-to-face interviews with childcare providers $(n=18)$ and Local Authority Early Years service staff $(\mathrm{n}=7)$ were conducted and explored food provisions and practices, connections between providers, parents, and policy makers, sources of nutrition information, values regarding the role of food in the health of a child, and the extent of which providers believe they have a responsibility to promote healthy eating habits to children. 
The results of the questionnaire showed that of the 168 respondents, $43 \%$ of the providers offered a full range of meals and snacks every day. Child-minders were more likely than nurseries to have parents provide the food for the children $(p<0.04)$. One quarter of child-minders and $8 \%$ of private nurseries reported that parents provided all the food (12). The majority of the respondents believed they had a critical responsibility in promoting health $(79 \%, n=133)$; however, it was common for childcare providers to receive little to no formal training in nutrition. Sources of nutrition information for childcare providers came primarily from peers, family, or cookbooks (12).

The interviews revealed that the providers' personal issues and experiences with food impacted their decisions as to what foods were served to the children (12). For example, due to being raised in an Italian family, one caregiver created an environment where food was the center of the day's activity. Another provider was concerned with her own weight and fed the children based on her personal diet of low carbohydrates. Regardless of the varying reasons of which foods to serve, providers often spoke negatively about the foods offered and the feeding practices of parents. Attempts were made to provide healthy meals dependent on personal knowledge of nutritious food.

The researchers categorized the participants into three types of groups that involved communication and implementation of food policy: Explicit Enforcers - openly state and implement their own food policy even if it differed from the parents; Covert Enforcers implement their policy by means of tact or deception in order to maintain their relationship with the parents; Conformers - comply with the parents wishes even they disagree. Overall, regardless of their group label, U.K. childcare providers felt as though their work was negated once the children ate at home. Not only that, but the parental concern with the cost of food rather than the nutritional content of meals was a recurring theme among the interviews. The lack of concern by 
parents made it difficult for caregivers and parents to work together to educate children on healthy eating.

The researchers believed that childcare providers are in a position to strongly influence the nutritional habits of young children and as with the previous study, there is a need for a partnership between parents and childcare providers in implementing healthy foods into children's diets. In-home caregivers may also have a strong belief in their influential power for promoting nutritional health and have the potential to manipulate a child's eating habits.

Sigman-Grant et al believed that "mealtimes should provide nutritious food and a supportive environment for young children to develop appropriate eating skills and to learn what to eat (13)." As so, the researchers inspected mealtime routines, policies, and training of staff and directors of childcare centers in four western states, which consisted of California, Idaho, Colorado, and Nevada. The study was conducted with the administration of two surveys one for staff and the other for directors. The Staff Questionnaire included eight topic areas: 1) current feeding practices, 2) degree of external adult control, 3) feeding routines, 4) barriers in creating optimal mealtimes, 5) personal feeding history, 6) current eating and physical activity behaviors, 7) height and weight, and 8) demographics. The Director Questionnaire was distributed to collect demographic, mealtime and training information about the childcare centers, as well as to confirm staff responses. A total of 568 childcare centers participated yielding 1190 staff and 464 director responses.

Results revealed that most mealtimes occurred in classrooms $(73 \%, \mathrm{n}=298)$ where a caretaker joined the children at the table and was responsible for serving food and drinks (13). Three key modes of food service were identified, 1) family style; children served themselves from larger platters 2) pre-plated; foods are put on plates and then served to the children, and 3) lunch box; some or all food was brought from home. Of the 367 staff, $57 \%$ practiced family style feeding, $8 \%$ pre-plated, and $31 \%$ lunch box. Data also showed that only $62 \%$ of the staff reported 
sitting at the table with children until mealtime was completed, $9 \%$ reported being in the room but not sitting at the table, and $29 \%$ said they sat with the children, however would often get up and down from the table.

In terms of the influential power on children, family style feeding was reported to encourage self-help skills and often led to smaller portion sizes served by the children themselves rather than when the adults served them. In a family style meal, the staff members were enabled to teach proper nutrition behaviors as well as promote safety, social skills, and serve as nutrition role models by trying new foods and teaching table manners (13). In fact, significantly more staff members from centers who practiced family style feeding talked to children about food (95\% $\mathrm{P}>0.001)$ as compared to pre-plated (79\%) and lunch box (77\%). Similarly, staff in family style food service tried new foods with the children $69 \%$ of the time compared to lunch box or preplated service, $40 \%$ and $42 \%$ respectively. Ultimately, it was found that pre-plated and lunch box meals lacked the opportunity of child development through the practices of self-regulation in regards to food intake.

While childcare facilities are governed by the state in which they reside, training regulations differ within each jurisdiction. The study found that $95 \%$ of the respondents were trained primarily in child development, while only $68 \%$ reported any training on nutrition (13). Training specific to feeding children was not mandated by any of the four states surveyed, however $2 / 3$ of the directors, $43 \%$ of the teaching staff, and $82 \%$ of the cooks reported receiving some sort of training on feeding children.

The authors expressed that Registered Dietitians can play a vital role in fostering modes of food service that positively influence eating habits of children and increasing nutrition education and training among the employees in licensed childcare centers. It is vital that these and other findings, perhaps of in-home caregivers, pave the future of nutrition education for childcare employees. 


\section{Childcare Centers and Nutrition Knowledge and Beliefs}

Universally, childcare personnel have exhibited low nutrition knowledge and have displayed inconsistencies within their corresponding beliefs and behaviors $(12,14,15)$. NahikianNelms conducted a study that attempted a holistic approach to childcare research addressing the physical environment of childcare facilities, caregiver behavior during meals, and the incorporation of appropriate nutrition education into the early childhood development prospectus (14). Three instruments were used to collect data. The nutrition knowledge questionnaire was a 20-item, multiple choice test that addressed common nutrition and diet concerns including the RDA, the USDA Food Guide Pyramid, and USDA Child and Adult Care Food Program (CACFP) guidelines (14). The second instrument was an attitudinal inventory of 27 items that addressed the role of nutrition in childcare programs, the position and beliefs of the caretaker in terms of implementing nutrition practices in early childhood development, and mealtime rules that may influence food preferences and eating behaviors (14). The final instrument was a behavioral checklist utilized during the observation portion of the study. The list was directed towards the interactions between caregiver and child during meals.

Twenty-seven licensed childcare programs in southern Illinois were contacted and informed of the study. A total of 113 caregivers participated; ages ranged between 18 and 66 years old and had a mean teaching experience of 5.8 years (14). The study yielded four sets of data: nutrition knowledge, nutrition attitude, caregiver behavior, and demographics (14).

Regardless of the fact that $69 \%$ of the caregivers reported having a nutrition course as part of their college curriculum, nutrition knowledge scores remained low. The sample averaged 10.9 points out of a possible score of 20 and less than half of the respondents correctly answered ten of the twenty questions (14). Only $13 \%$ correctly defined the RDA, while $80 \%$ thought sugar caused diabetes mellitus (14). Several participants were not able to identify the best sources of protein, vitamin A, and iron however scored high when recognizing the best sources of calcium, 
foods high in carbohydrates, and the nutrients that provide energy. Additionally, $49 \%$ of the respondents did not know that two-thirds of a child's nutrition needs must be met when a child is under childcare supervision for eight hours or more (14).

The childcare workers $(n=113)$ scored 69 out of a possible 81 points on the attitudinal inventory (14). A high score indicates that the caretaker had beliefs that should have positive influence on the children's development of healthy eating and food preferences. Approximately $86 \%$ agreed that they influence the eating habits of children when eating with the children. Accordingly, $95 \%$ of the respondents agreed with the statement, "caregivers should eat with children during meals in order to model good eating habits (14)." Three-fourths of the participants agreed that it was important for caregivers to consume the same food as the children during meals and snacks (14). However, caregivers contradicted their personal beliefs because they were observed sitting with the children for only $69 \%$ of the meals and of those who sat with the children, only $53 \%$ ate the same foods (14).

Nutrition knowledge and attitudes were positively correlated $(r=.37, p=.0001)$, meaning that those who scored high on the nutrition knowledge test were most likely to score high on the attitudinal inventory and ultimately determined how caregivers behaved during mealtime (14). Little nutrition education appeared during mealtime. Rather, a great deal of teacher-child interaction took place for discipline and rule setting. Overall, while the employees of the childcare centers believed they had a great influence on the nutritional habits of children, observations proved that their actions did not always support their beliefs. As a result, the prospect to function as a positive nutritional role model was negated. If this is true for all caregivers, children will lose valuable opportunities to develop healthy food preferences. Researchers in another study recognized the need to understand the strength and weaknesses of the childcare menus especially in facilities that participated in the USDA Child and Adult Care Food Program (CACFP) (15). The goal of the study was to provide data that 
would enhance guidance, training, technical, and financial assistance from CACFP. The sample for the study consisted of three prominent ethnic groups: African American, Hispanic, and Anglo (15). The research assistants visited nine centers in Texas to collect menus; "weigh and measure foods served to the children; interview staff and children about the food and the food program at their center; observe food storage, preparation, service and consumption; inspect links between the food program and other components of care at the center; and compare what [was] on the shelves of grocery stores with what [was] on the menu at the childcare center (15)."

Ultimately, the content of menus was based on program obligations, for example CACFP requires sources of vitamin $C$ to be served every day, while vitamin $A$ should be served every other day (15). Through observation and communication with the foodservice personnel, data revealed that childcare workers had clear intentions to meet all requirements, however the capabilities to adhere to the guidelines were limited by their lack of nutrition knowledge. By examining the daily activities of the staff, employees displayed deficiencies in basic knowledge of food and nutrition, food safety, and math skills to properly measure and serve food (15). Only one center had a systematic approach to weigh or measure both fresh and packaged foods for cooking and serving. The other facilities based their food preparation solely on package sizes, such as serving the minimum amount of applesauce based on ladle size (15). With this, rather than guessing how many portions a fresh apple will provide, directors knew exactly how many portions of applesauce a can will supply based on the minimum requirements set by CACFP (15). Poor nutrition knowledge also was exemplified when staff at one center believed that brown sugar was healthier than white sugar while workers at another facility assumed that bottles of orange drink were "full strength juice" due to the fact that they did not have to add any water (15). Without any basis, caregivers assumed that children did not like or would not eat vegetables. With this mindset, one center prepared a can of carrots as plate decoration rather than a side dish. Observational results showed that $25 \%$ of the children at the center requested more of the carrots 
than were served, demonstrating that the caregiver's assumptions on the children were erroneous. Essentially, staff at the childcare centers believed that the purpose of the preparing and serving meals to the children was to "fill them up," rather than providing sensible and healthy foods that meet CACFP guidelines (15).

Food and nutrition education was not an essential component of care in any of the centers (15). Although the caretakers enticed children to eat, they rarely discussed where foods came from or why specific foods were healthy to eat. As so, the nutrition knowledge of the children proved to be poor as well. One observer reported that while many of the children knew milk came from cows, several affirmed that milk came from bottles in the factories manufactured them.

Furthermore, food safety was compromised due to low nutrition knowledge (15). Foodservice personnel often cooked foods in the early part of the day leaving foods on low heat for two to three hours at a time (15). Children were often allowed to sit at the tables while the cooks or caretakers carried pots of food over the children's heads. Rodents were found in every kitchen and observational data revealed that most kitchens were not properly cleaned and sanitized. In fact most centers used the same mop to clean the restrooms and kitchen. The nature of the violations was found not to be of careless endangerment, but of a true lack of food and safety knowledge (15). Overall, the capabilities to produce high quality menus to fulfill the program and nutritional requirements were greatly compromised due to the low nutrition knowledge of the childcare workers. In addition, low knowledge in food safety and nutrition can greatly affect the wellbeing of a child.

\section{Childcare Centers and Feeding Behavior}

Childcare workers, as with parents, display varied forms of feeding behavior. Past research has labeled these feeding behaviors into three categories; authoritarian, authoritative, and permissive (16). Authoritarian behavior is characterized by the extreme external control of the caregiver whom often displays restrictive behaviors and power-assertive directives. Authoritative 
behavior offers control over a child's eating through reasoning and involvement. Permissive behavior is typified by the lack of structure provided and often leads to nutritional neglect where the child is encouraged to eat the desired foods in the quantities the child chooses. According to Hughes et al, no studies have systematically investigated these feeding behaviors in the natural setting of a childcare facility and examined the observed feeding styles and actual food consumption of the children. As so, the purpose of the study was to "examine feeding behaviors exhibited by childcare providers, specifically in Head Start centers, to test the association between self-reported feeding styles and observed feeding behaviors, and to examine the role of feeding behaviors on the food consumption of the low-income minority children (16)."

Fifty childcare employees and 549 African-American and Hispanic children, age three to five, were randomly selected from thirteen Head Start centers in Houston, Texas (16). The researchers employed both an observational method as well as a self-reported questionnaire. Each childcare employee was observed three times during separate lunch occasions. The 22 -item measure known as the Feeding Behavior Coding System (FBCS) was utilized to document frequency behavior across five food groups (fruit, vegetables, dairy, entrée, starch) and specific feeding behaviors and styles cataloged as authoritative (reasoning/explaining), authoritarian (physically struggling/showing disapproval), and two permissive behaviors known as indulgent (offering more servings), and uninvolved (ignoring) (16). The FBCS was essentially an observational checklist of the self-reported Caregiver Feeding Styles Questionnaire (CFSQ) (16).

Hispanic caregivers more often displayed authoritarian $(p<.01)$ and authoritative $(p<.05)$ behaviors than African-American providers (16). No statistically significant differences were found between ethnic groups for either of the permissive feeding styles. A significant correlation was reported between self-reported permissive and observed indulgent behaviors $(p \leq .05)(16)$. Self-reported and observed authoritative behavior were moderately correlated $(r=.24, p=.07)(16)$. No correlation existed between self-reported and observed authoritarian feeding styles (16). 
Specific styles, such as authoritative and indulgent, demonstrated a positive influence on a child's eating habits. Authoritative behavior by the caregiver resulted in a greater consumption of dairy among children. Indulgent feeding styles were "positively associated with children's consumption of vegetables, dairy, entrée, and starch (16)." Childcare providers revealed fairly low levels of authoritarian feeding $(\mathrm{M}=1.65, \mathrm{SD}=0.40)$, which may be the result of regulations set by Head Start in regards to interaction between caretaker and child (16). Overall, children were more apt to eat foods, regardless of nutritional quality, when feeding behaviors included forms of encouragement and enlightenment. It is important to consider feeding styles when determining influential roles childcare givers may have on children.

\section{Summary of Literature Review}

Although one study indicated that nannies have an influence on children, it was conducted more than 30 years ago, without a follow up study, and focused on race rather than food. Six studies centered on childcare facilities and their nutrition knowledge, feeding styles, and nutritional beliefs regarding children. Research showed that caregivers indeed influence children at mealtimes in childcare centers. While the level of nutritional influence varied among caregivers, there was consensus that regardless of the influence a caretaker may have, parents were ultimately responsible and often negated the actions of the caretakers from the childcare facilities. Regardless of the caretakers' influential beliefs, promoting healthy eating was deterred due to the lack of proper training in childhood feeding and food safety, unhealthy personal eating habits, and unreliable sources for nutrition education. Ultimately, these factors led to low nutrition knowledge scores among employees in childcare centers. Furthermore, the type of feeding style, whether authoritarian, authoritative, or permissive, had an impact on a child's eating habits. While all the studies provided meaningful results, the role of in-home childcare providers, such as nannies, in regards to nutrition knowledge, feeding behaviors, and beliefs on how they may influence children, is still unclear. 


\section{Conclusion}

Studies on employees of childcare centers and their influence on the nutrition of children are scant. The current studies demonstrate that these individuals, who are not related to the children, influence the child's eating behavior and nutritional status. While some evidence exists that employees in childcare centers have an impact on the nutritional behaviors of children and that their nutrition knowledge is low, similar research is lacking with nannies. Therefore research is warranted to investigate the nutrition knowledge, feeding styles, and feeding behaviors of nannies. The results of the study will provide new information on the nutritional practices of this untapped genre of childcare personnel and may bring focus on the need to educate nannies regarding their nutritional impact on a child's health and development. 


\section{METHODOLOGY}

\section{Sample}

A descriptive, cross-sectional study was conducted during the spring of 2010 to investigate professional nannies' nutritional knowledge, feeding behaviors, and beliefs. The inclusion criteria for the nannies were: 1) men or women 18 years of age and older; 2) currently working or looking for hire as a nanny and 3) recruited through one of three professional nanny organizations, Association of Premier Nanny Agencies, International Nanny Association, and the National Association for Nanny Care. Nannies were excluded if they were related to the family receiving their childcare services. The Institutional Review Board of Florida International University approved the study.

\section{Instrument}

The survey, "Knowledge, Behaviors, and Beliefs of Nannies in Regards to Nutrition and Children," was a self-administered questionnaire consisting of 59 questions divided into four sections (Appendix I). Part one collected general information and demographics through 20 multiple choice and open-ended questions; part two had 10 multiple choice questions to determine nutrition knowledge; part three included 19 questions, in a Likert scale format, pertaining to feeding behaviors; and 10 questions in part four examined beliefs on the nutritional influence on children through a multiple choice and Likert scale format.

With the exception of the Caregiver's Feeding Style Questionnaire, the instruments presented in the literature review offered limited access and consequently, were not obtained. Therefore, the current instrument was adapted from four previously administered and validated questionnaires employed in alternative studies $(17,18,19,20)$. Evans' survey was screened for content validity and tested the nutrition knowledge of Wisconsin elementary teachers and food service managers (17) (Appendix II). The questionnaire developed by Hawkes and Nowak was tested for internal reliability with a Cronbach's alpha of 0.76 (18) (Appendices III). Holland's 
dissertation survey was examined for internal validity and investigated childcare providers' perceptions of their influence on young children while the Caregiver's Feeding Style

Questionnaire developed by Hughes et al was tested for convergent validity $(19,20)$ (Appendices IV and V).

Ten questions from the demographics section, as well as four questions from the beliefs section, were variations of the survey conducted by Holland (19). The nutrition knowledge section included five questions modified from a questionnaire Evans' developed and four questions were adopted from the Hawkes and Nowak's questionnaire $(17,18)$. The feeding styles section was a derivative of the Caregivers Feeding Style Questionnaire (CFSQ) promoted by Hughes et al (20). The remaining 17 questions were developed based on the literature review.

\section{General Information and Demographic Section}

Part one of the questionnaire asked 20 demographic questions (Appendix 1). When the words "caretaker at the childcare facility" were in the statement, they were changed to the word "nanny." The following closed-ended statements with fixed multiple choice answers were changed to forced-choice questions: "my gender is," to "what is your gender?"; "my birth date is" to "what is your age?"; "I have been employed in the childcare profession for" to "how many years have you been employed in the childcare profession?"; "the number of children in my class is" to "how many children do you currently care for as part of employment as a nanny?"; "the age of child I am primarily assigned to teach is" to "what is the age of the children you currently care for as part of your employment as a nanny?"; and "the last training workshop on nutrition that I attended for my job was" to "when was the last nutrition workshop, class, lecture, and/or information session you attended?" The statements "my race is" and "the highest level of education I completed is" were changed to "what is your ethnicity?" and "what is the highest level of education you have received?" respectively. With these two questions, the fixed responses also included the choice of "other" where the respondent could write in a response for 
"other." The statement, "my current employment status in the childcare profession is" was reworded to "what is your current employment status as a nanny?" This was asked twice. One had the options of "full-time (40 hours per week or more);" "part-time (less than 40 hours per week);" "not currently working as a nanny but looking for hire;" and "not currently working as a nanny and not looking for hire." When asked again, the response choices were live-in or non-livein employee.

Five questions were not obtained from previous studies or questionnaires. For two of the questions, participants selected the agency with which they were affiliated from a list of three and responded either yes or no to being related to the family that employed them. The response determined inclusion and exclusion of the participant. Three open-ended questions were included to examine the regional location of the respondents: "From what country did you receive your highest level of education?"; "What state do you currently live in?"; "What state(s) do you work in as a nanny?" Five questions were derived from the review of literature. They inquired about the following: the number of families that employed the nanny; the average yearly income of the family that employed the nanny; if the nanny is employed by a single- or dual-parent household; if the nanny had his/her own children; and from what sources did the nanny receive their nutrition information.

\section{Nutrition Knowledge Section}

Part two of the survey included 10 questions to determine the basic nutrition knowledge of the nannies (Appendix 1). Five forced-choice questions from the Evans' study were modified to include more answer options and to reflect current nutrition guidelines (17). The first multiple choice question "which of the following groups lists $O N L Y$ nutrients?" had four options and was changed to "classify the following as either a FOOD or NUTRIENT" with 10 foods or nutrients. The foods and nutrients were in a table format and the respondent could choose either "food;" nutrient;" or "not sure." Two other questions were, "a kilocalorie (calorie) is a measure of" and 
"which of the following is a TRUE statement?" However, one of the answer options for the latter question was altered to read "calorie" rather than "energy." A fourth question "which of the following meals contain foods from each of the basic four food groups?" was changed to "which of the following best represents the dietary guidelines of the United States' Food Guide Pyramid?" Here the answer options were slightly modified to meet the current nutrition guidelines. The inquiry regarding food safety, "which of the following makes food safe?" was an expansion of Evans" "food contamination may result from." Five food safety practices were formatted into a table and participants chose one of the following options of "yes;" "no;" or "not sure."

For the statement, "cholesterol is found in only in animal products," directly from the Hawkes and Nowak's questionnaire, the respondents were requested to mark either true or false. From the same questionnaire, another true or false question was slightly modified to read "the main ingredient in a food is listed FIRST on a food label" rather than "the main ingredient in a food is listed LAST on a food label." The answer options for the question "which has less fat" included "butter;" "vegetable oil;" "they are equal;" and "not sure." The original question offered the answer "margarine" rather than vegetable oil, and the change was made to make the food items less identical. Hawkes and Nowak asked, "do these foods have fibre?" In the current survey the spelling was corrected and it was adjusted to read, "which of these foods have fiber?" One of the answer options, "bread," was changed to "whole wheat bread" to further specify the type of bread.

The question, "which of the following are paired correctly?" was based on the literature review. Five foods were each paired with a nutrient and listed in a table. The respondents chose one of three options: "Yes, paired correctly," "No, not paired correctly;" and "Not Sure." 


\section{Nutrition Behaviors and Beliefs Sections}

The third part of the survey had 19-questions which when analyzed would indicate one of four feeding styles: authoritarian, authoritative, indulgent, or uninvolved. The questions were taken directly from the CFSQ developed by Hughes et al. The order in which the questions were listed, as well as the wording, were modified and directed specifically towards nannies. This section was partitioned into two segments. The first segment included nine quotes a nanny may say to a child during mealtime and the second segment incorporated 10 questions on how the nanny may conduct him or herself when the child is eating. To indicate the frequency of the behavior, the nanny could choose one of the following for each of the 19 statements: "Never;" "Rarely;" "Sometimes;" "Most of the Time;" and "Always."

The first segment listed nine various quotes. To better describe a feeding behavior where the caregiver used food as a reward or punishment, the statements, "if you finish your vegetables, you will get some fruit" was changed to "if you finish your vegetables, you will get some ice cream and "if you don't finish your vegetables, you wont get fruit" was changed to "if you don't finish your vegetables, you won't get candy." The following three statements were also adjusted: "what a good boy! you're eating your beans" to "what a good boy! you're eating your vegetables"; "your dinner is getting cold" to "eat your dinner, it is getting cold"; and "eat your beans" to "you need to eat your fruit." Four statements were identical to the originals: "if you eat your beans, we can play after dinner"; "hurry up and eat your food"; "milk is good for your health because it will make you strong"; "if you don't finish your meal, there will be no play time after dinner."

The second segment consisted of various behaviors that may occur during a child's mealtime. Here too, the descriptions of the behaviors were moderately altered. Three were reworded to make the question concise, yet comprehensible: "encourage the child to eat by arranging the food to make it to more interesting" to "arrange the food to make it interesting (for 
example, making smiley faces on the pancakes)"; "ask the child questions about the food during dinner" to "ask the child questions about food"; and "physically struggle with the child to get him or her to eat (for example, physically putting the child in the chair so he or she will eat)" to "restrain a child reluctant to eat." Three descriptions were taken verbatim from the CFSQ: "tell the child to eat at least a little bit of food on his or her plate"; "help the child to eat dinner (for example, cutting the food into smaller pieces)"; and "beg the child to eat dinner." In the remaining four descriptions, "the meal" replaced "dinner" from the original questionnaire. They are as follows: "say something to show your disapproval of the child for not eating the meal"; "allow the child to choose the foods he or she wants to eat for the meal from foods already prepared"; "say something positive about the food the child is eating during the meal"; and "spoon-feed the child to get him or her to eat the meal."

The fourth and final part of the survey gathered additional data on the behaviors of nannies during mealtimes and information pertaining to the nannies' personal and professional beliefs regarding the nutritional influence they may have on the children in their care. This section included 10 questions; six were based on the review of literature and four were obtained from Holland's study. Five of the six questions derived from the literature were centered on food and snack choices: "who shops for the food and/or snacks that the children you care for eat?"; "who decides what food and/or snack choices the children have to eat?"; "do the parents consider/value your opinion when it comes to what foods and/or snacks to give the children?'; "do you give the child (children) snacks?"; "how often is (are) the child (children) given snacks?" The sixth question asked, "do any of the children you care for as a nanny require special dietary needs?"

Holland's study provided the four remaining questions. Three focused on nutritional influences nannies believed they had on children under their care and one obtained additional feeding and eating behaviors of nannies. Only one of the questions maintained in a multiple- 
choice format and asked, "the person(s) who has/have the greatest influence on eating habits of the children you care for is/are." Compiled from several individual questions found in the original survey, the three questions, "as a nanny, the importance you place on: (4 beliefs listed)"; "as a nanny, you would describe your influence on: ( 2 beliefs listed)"; and "how often do the following [behaviors] occur?" were formatted into a Likert response scales.

\section{Expert Panel}

Four experts in the fields of nutrition, nutrition education, and child and family behavior were consulted to review the instrument. The evaluation yielded minimal change, however recommendations included rewording for clarification, grouping like questions, and adding items of interest. Such items included inquiring whether nannies cared for children with special dietary needs, if the nannies had children of their own, and the states where the nannies lived and worked. The expert panelists approved the survey and the electronic format in which it was to be distributed.

\section{Pilot Study}

A pilot test of the survey was conducted in October of 2009 with five nannies and one director from each of the three professional nanny associations. Participants received the electronic version of the survey via email. The survey for the pilot study included an additional section at the end of the questionnaire where the respondents were able to openly write comments, questions, concerns, and/or suggestions regarding the survey's aesthetic appeal, the ease and readability, and the format and content of the questions. Of the seven who completed the survey, five provided comments; one corrected the name of a nanny association; one indicated she was not able to save her progress without printing the survey; five agreed the content and questions were relevant to the study; and five stated that the navigation through the online survey was simple. 
In evaluating the feedback, the name of the nanny association was corrected and the settings of the online survey were set so that respondents were able to navigate backward and forward through all the sections of the electronic survey until it was completed. However, once the survey was finished and the respondent exited the webpage, the respondent was not allowed to re-enter the survey. At the end of the instrumentation process, the final questionnaire included four sections with 59 questions.

\section{Procedures}

Once the instrumentation was developed, a web-based survey was designed, created, and administered through SurveyMonkey ${ }^{\mathrm{TM}}$. All three professional organizations were contacted to request permission to conduct a survey among its members. On May 3,2010, the web link to the survey was emailed to the directors of the associations who in turn provided the web link to their members via mass email, newsletters, company websites, blogs, and social networking sites. Prospective participants' names and physical and email addresses were not provided due to privacy agreements among the associations and its members. The electronic version of the survey comprised of a consent form, including a purpose statement, and the questionnaire with an estimated completion time of approximately thirty minutes. The directors of all three professional organizations were informed that the survey was available online for six weeks with a closing deadline of June 13,2010. At weeks three, four, and five, an email was sent to the directors as a reminder to prompt their members to complete the survey. All surveys were saved with an identifying number to maintain anonymity.

\section{Statistical Analyses}

The power for the study was determined by G-Power software (version 3.0.10, 2007, Germany) (21). To obtain $95 \%$ power for the t-tests for a medium effect size $(\omega=.5)$ a sample size of 210 was sufficient. 
Statistical data were analyzed with SPSS for Windows (Version 18.0.0, 2009, SPSS, Inc. Chicago, IL). Descriptive statistics, frequencies, and percentages or means were calculated for all variables. Spearman's rho was used to find correlated age, education, and years of employment with knowledge. Chi-square and Kruskal-Wallis tests were used to compare the responses of nutritional beliefs and feeding styles with participants' age, education, and years of employment. Knowledge scores were computed based on a 32-point scale where one point was given for correct answers and zero points were given for incorrect or not sure answers. Feeding styles were determined based on typological scoring algorithms established by the originator where two sets of scores determined demandingness, the total means score calculated across all items, and responsiveness, the ratio of child-centered items over the total means score. Participants were categorized into feeding styles based on the scores for demandingness and responsiveness: authoritative $=$ high demandingness/high responsiveness; authoritarian $=$ high demandingness/low responsiveness; indulgent = low demandingness/high responsiveness; and uninvolved $=$ low demandingness/low responsiveness. Tests were statistically significant if $p<$ .05 . 


\section{RESULTS}

Eighty-three surveys were submitted via electronic correspondence. Unbeknownst to the cause, an average of 13 respondents failed to answer numerous questions subsequent to the demographics section. Due to privacy guidelines and confidentiality agreements among the Associations and its members, the dissemination of the survey web link was at the discretion of the directors. Therefore, it was difficult to determine the exact number of nannies that received the survey and thus a response rate was not calculated. Because some respondents did not answer all the questions, the results are based on differing sample sizes.

\section{Demographics}

The majority of the participants were White American or Caucasian $(94 \%, n=78)$ women $(100 \%, n=83)$ (Table 1). Over half the nannies were aged $25-44(64 \%, n=53)$ with none of the respondents older than 64 years. Eighty-eight percent of the nannies had some form of education beyond high school. All nannies had been employed for at least one year or more with the most employed $11-20$ years $(41 \%, n=34)$. More nannies did not live with the family than did. The majority of nannies worked on a full time basis $(73.2 \%, n=60)$ for only one family $(77 \%, n=64)$ that was a dual parent household $(91.6 \%, \mathrm{n}=76)$. The majority of nannies cared for one to three children with the children ranging in age from infancy (birth to 12 months) to adolescence (8-14 years). While $26.5 \%(n=22)$ of nannies were "not sure" the income of the family that employed them, $61.4 \%(n=51)$ reported that the average yearly income of the family was more than $\$ 100,000$. A majority of nannies $(80.5 \%, \mathrm{n}=66)$ reported they did not have children of their own. Although the majority of the nannies $(77.9 \%, \mathrm{n}=53)$ did not care for children with special dietary needs, 15 nannies $(22.1 \%)$ reported that they did care for children who require dietary attention. Respondents represented all four regions of the US as well as Canada and Europe (22) (Table 1). Many of the nannies either lived or worked in the western or southern regions of the US. Twelve nannies never attended any nutrition instruction session, while the majority $(63.5 \%$, 
$\mathrm{n}=52$ ) attended some form of nutrition information session within the last three years (Figure 1). The print media was the primary source of nutrition information for the nannies with food labels the second (Table 2$)$. Only $6 \%(\mathrm{n}=5)$ utilized conferences, workshops, or classes.

\section{Nutrition Knowledge}

Nutrition knowledge scores were based on 32 questions and calculated on total points correct (Table 3). Nannies' mean raw score was 24 out of 32 points resulting in $75 \%$ correct in nutrition knowledge. There was no significant correlation between nutrition knowledge scores and age $(p=.512)$, highest level of education $(p=.728)$, or years of employment $(p=.469)$.

Nannies were proficient in differentiating between a food and nutrient (Table 4). When asked if a food and nutrient were appropriately coupled, the majority of nannies correctly identified three of the five pairs (Table 5). There were discrepancies for ground beef and vitamin $\mathrm{D}$ and whole wheat bread and vitamin B12. The majority of nannies correctly identified baked beans $(92.8 \%, n=64)$, whole wheat bread $(97.1 \%, n=68)$, and oranges $(71 \%, n=49)$ as having fiber and steak $(73.5 \%, n=60)$, apple juice $(55.2 \%, n=37)$, and fish $(84.6 \%, n=55)$ as not having fiber.

Sixty-eight percent $(n=47)$ of nannies marked "false" for the statement "cholesterol is found only in animals products", while $29 \%(n=20)$ correctly selected "true" and $2.9 \%(n=2)$ were "not sure." A large percentage of nannies agreed that the main ingredient in a food was listed first on a food label $(90 \%, \mathrm{n}=63)$, while a smaller percentage answered either "false" $(8.6 \%$, $n=6)$ or "not sure" $(1.4 \%, n=1)$. Of those who responded, only one chose the incorrect meal that represented the dietary guidelines of the USDA Food Guide Pyramid. Vegetable oil was selected to have less fat than butter $(42.9 \%, n=30)$, however, $30 \%(n=21)$ considered them equal in fat and $17.1 \%(n=12)$ were not sure. Only $10 \%(n=7)$ responded to the question correctly.

Of the four proposed definitions for kilocalorie, $54.4 \%$ chose the correct answer (Table 6). All but four respondents correctly recognized "calorie intake in excess of an individual's requirements is stored in the body as fat" as a true statement (Table 7). The majority of the 
nannies correctly answered three of the five food safety questions. There were variations in answers regarding freezing foods to kill bacteria and the temperature at which a refrigerator should be set (Table 8 ).

\section{Nutrition Behaviors}

\section{Foods and Snacks}

Seventy-seven percent $(n=64)$ of nannies responded that parents considered their opinions for foods and snacks served to the children (Figure 2). Sixty-three of the 68 nannies that responded gave snacks to the children in their care. Forty-four percent $(n=30)$ reported that both the parents and nanny shopped for foods and snacks the children ate. Based on multiple responses of the nannies, $72 \%(n=49)$ of nannies and $63 \%(n=43)$ of parents decided what food or snack choices the children had to eat (Figures 3,4).

Eighty-seven percent $(\mathrm{n}=58$ ) always, most of the time, or sometimes ate the same foods served to the children while $69 \%(n=47)$ sometimes, rarely, or never brought food from home (Table 9). The majority never, rarely, or sometimes ordered from a restaurant for pick-up or delivery to feed themselves or the children, $(98.5, n=67$ and $100 \%, n=68$, respectively). In the same respect, $98.5 \%(n=67)$ of nannies never, rarely or sometimes took the children to eat at a fast-food or other restaurant. The percent of nannies that sometimes, most of the time, or always ate with the children was the same at $31.8 \%(n=21)$. Most nannies reported never skipping meals while caring for the children $(52.2 \%, \mathrm{n}=35)$ or rarely cleaned while the children ate $(34.8 \%$, $\mathrm{n}=23$ ). Nannies were consistent with behaviors and tests revealed a statistically significant difference for age and the statement "I eat the same foods served to the children," $X^{2}(4, n=67)=$ $11.37, p=.023$

\section{Feeding Styles}

A typological approach was utilized for aggregating feeding styles based on 19 questions, seven were child-centered and 12 were nanny-centered. Nannies were asked to choose "never," 
"rarely," "sometimes," "most of the time," or "always" to describe the frequency of the behaviors. A ratio of the answers was used to categorize a participants' feeding style. Of those who responded, nannies displayed more authoritarian $(35.8 \%, \mathrm{n}=24)$ and indulgent $(32.8 \%, \mathrm{n}=22)$ forms of feeding than authoritative $(14.9 \%, \mathrm{n}=10)$ and uninvolved $(16.4 \%, \mathrm{n}=11)$ behaviors. A statistical significance between feeding styles and age, highest level of education, or years of employment was not identified.

The majority of nannies chose "never" for the following statements, "if you finish your vegetables you will get some ice cream $(57.1 \%, n=40)$;" "if you eat your beans, we can play after dinner $(71.4 \%, n=50)$;" "if you don't finish your meal, there will be no play time after dinner $(77.1 \%, n=54) ;$ " and "if you don't finish your vegetables, you won't get candy $(81.4 \%, n=57)$ (Table 10)." Although most nannies chose "never" for the statements, "eat your dinner, it's getting cold $(37.7 \%, \mathrm{n}=36)$;" and "hurry and eat your food $(48.6 \%, \mathrm{n}=34)$;" there were more variations within the answer choices. "Milk is good for your health because it will make you strong" and "you need to eat your fruit" were said "most of the time" during a meal by $31.4 \%$ $(\mathrm{n}=22)$ and $33.3 \%(\mathrm{n}=23)$ of the nannies, respectively. The statement, "What a good boy! You're eating your vegetables" also displayed variant answers.

Most nannies reported they "never" restrained a child reluctant to eat $(88.6 \%, n=62)$ or begged the child to eat dinner $(85.7 \%, \mathrm{n}=60$ ) (Table 11). Nannies "rarely" said something to show disapproval of the child for not eating the meal or spoon-fed the child, $43.5 \%(n=30)$ and $38.6 \%(n=27)$, respectively. The majority of nannies either "sometimes" or "most of the time" arranged food to make it interesting $(70 \%, \mathrm{n}=49)$, asked the child questions about the food ( $80 \%$, $\mathrm{n}=56$ ), told the child to eat at least a little bit of food on his or her plate $(75.3 \%, \mathrm{n}=52)$, or helped the child eat dinner $(68.1 \%, \mathrm{n}=47)$. Nannies almost always said something positive about the food the child was eating during the meal $(80 \%, \mathrm{n}=56)$ and selected diverse answers when asked if they allowed the child to choose the foods he or she wanted from foods already prepared. 


\section{Beliefs - Nutritional Influence on Children}

A statistical significance was identified for years of employment and the statement, "serving the children meals and snacks that you would consider nutritious," $X^{2}(3, n=67)=14.17$, $p=.003$. No statistical differences or correlations were found between the nannies' nutritional beliefs and highest level of education.

Fifty-four percent ( $n=45$ ) of nannies believed that parents or guardians had the most influence on the eating habits of children while only one-fifth of the nannies believed it is they who had the greatest influence (Figure 5). The majority of nannies perceived they had a high influence on the nutrition habits and the nutrition education of children in their care (Table 12).

Nannies concurred that it is very important to assist children in maintaining a healthy weight $(60.3 \%, n=41)$ and aiding those who are overweight in losing weight $(37.3 \%, n=25)$ (Table 13). Accordingly, $92.5 \%(n=62)$ believed it was very important to serve meals and snacks that they considered nutritious. Forty-nine of sixty-eight nannies also believed it was very important that children receive appropriate nutrition education during early childhood years. 


\section{DISCUSSION}

Childcare in the home setting is an emerging trend, however research is lacking when it comes to examining the role of non-relatives, specifically nannies, on the nutrition of children. The current body of literature explores feeding roles and nutritional influences of non-parental caregivers in state-licensed childcare centers who often participated in government mandated and subsidized nutritional programs $(11,12,13,14,15,16)$. This present study investigated nannies' nutrition knowledge and feeding behaviors as well as their beliefs on whether they influence a child's eating habits.

\section{Demographics}

According to the United State's Census Bureau, the sample represented different regions of the country. The majority of the respondents were White or Caucasian women in their midtwenties to mid-forties. It is uncertain why there was a lack of respondents over the age of 65 , however it is possible that adults of this age did not have computer access for participation in a web survey. Overall, demographic data mirrored the population surveyed by the International Nanny Association (INA) in a 2009 salary survey (23). Ethnicity and age were not available through the INA survey, however their study of 667 in-home child-care providers found that $84.2 \%$ had some form of education beyond high school. Not only are nannies' education levels consistent with these findings, but also with a previous study that reported childcare staff as primarily having an associate's degree or some college (23). Similarities also became apparent for years of employment, employment status, and work environment (23). Nannies of the INA survey also reported to caring for one to three children between the ages of birth and 14 years old.

Although the majority of nannies did not care for children with special dietary needs, the percentage that did, exceeded those surveyed through the INA (23). Special needs included allergies to various foods, sensory issues that hinder willingness to try new foods, celiac disease, autism, acid reflux, lactose intolerance, and strong food aversions. It is important to note that the 
highest score of the total sample was 30 out of 32 points, achieved by a nanny who cared for a child with special dietary needs. These findings are reassuring, as children who require special dietary needs must be under the care of knowledgeable individuals so that optimal nutrition intake is ensured. It was also established that these nannies displayed more indulgent feeding styles. It is probable that the higher prevalence of an indulgent feeding style was due to the compassion and consideration of the child's strict diet, where the nannies were likely to allow the children to eat more of the allotted foods in their special diet.

The majority of the respondents were present at some form of nutrition education session within the last three years. While this is valuable, it is important to note that approximately onethird of the nannies' attendance in a nutrition education session was more than five years ago or they have never attended a session. This may have been a contributing factor to overall low nutrition scores. Additionally, there was a discrepancy between the last nutrition education session attended and source of nutrition information. While the majority of nannies accessed print media as their source for nutrition information, only $6 \%$ utilized conferences, workshops, or classes. This is a small percentage considering more than half of the nannies reported they recently attended a nutrition education session. Despite the incongruity, sources of nutrition information for nannies were similar to childcare workers in a previous study where the researcher found that print media largely contributed as a source of nutrition information (24). Food Labels were the second most popular source for nutrition information. The possibility that nannies are utilizing food labels to evaluate the nutrition value of food is promising. Overall though, the use of food labels by the American population is rising, and nannies fall within the three most influential factors that contribute to label reading; gender, age, and education level $(25,26)$. 


\section{Nutrition Knowledge}

Previous research indicated very low nutrition knowledge among caretakers in childcare centers $(12,14,15)$. In contrast, nannies' nutrition knowledge scores indicated an average passing grade of a "C." These results were much higher than caretakers of earlier studies who achieved a mean score of 10.9 out of a possible 20 points (14). Furthermore, when compared to other populations, nannies achieved higher scores in nutrition knowledge than teachers and nurses who scored 19.6 out of 31 points and averaged a $65 \%$, respectively $(27,28)$. Overall nutrition knowledge scores for the nannies ranged from 14 to 30 points, indicating variability among nutrition knowledge levels of nannies. This range of knowledge scores may reflect the varying time spans of nutrition sessions attended by the nannies.

Nannies were asked various questions pertaining to food and nutrients. From 10 items, nannies correctly classified meat, milk, and eggs as food and protein, calcium, carbohydrates, sodium, niacin, fat, and iron as nutrients. Iron and calcium were the only items correctly identified as a nutrient by all respondents. Although correctly classified, nannies were most unsure about carbohydrates, fat, niacin, and sodium. When asked to associate the foods and nutrients that were most appropriately coupled, nannies had most trouble dissociating ground beef and vitamin D and whole wheat bread and vitamin B12. Nannies were able to correctly identify the foods that did and did not have fiber, however steak, apple juice, fish and oranges caused the most uncertainty. The ability to recognize foods and nutrients is consistent with previous research (27). However, nannies in this study were more adept at distinguishing single items rather than knowing the foods that have specific nutrients. Additionally, nannies reported that food labels were the second most used source for nutrition information. This source is inadequate if nannies cannot make the connections between foods and the nutrients they supply.

Agreeing that cholesterol was not only found in animal products was consistent with previous research findings that knowledge on cholesterol was lacking and has declined (29). 
Utilizing food labels as a secondary source of nutrition information may have contributed to the nanny consensus that the main ingredient is listed first on a food label. Vegetable oil was selected to have less fat than butter, however this is incorrect. Vegetable oil is higher than butter in monounsaturated and polyunsaturated fatty acids, which raises the total fat content (30). Overall, the media is responsible for a barrage of nutrition information disseminated to the public. Pairing foods and nutrients and complex issues are not the focus of the media. Rather, the same basic nutrition knowledge (or misinformation) is circulated, contributing to low nutrition knowledge.

More than half of the nannies correctly defined a kilocalorie. However, almost one quarter of the nannies believed a kilocalorie was defined as the amount of heat required to digest the food we eat. This definition is moderately similar to the scientific definition of a calorie, the quantity of heat needed to raise the temperature of $1 \mathrm{~kg}$ of water from 0 to 1 degree Celsius. If previously referenced by the nannies, the slight change of words may have caused confusion (31). All but four nannies understood that calorie intake in excess of an individual's requirements is stored in the body as fat. This is a positive finding, however, for nannies that display indulgent feeding styles where food is offered in unlimited amounts, their actions may not necessarily coincide with what they know.

The majority of the nannies correctly answered the questions concerning food safety, however there was inconsistency in regards to freezing foods to kill bacteria and the temperature at which a refrigerator should be set. Seventeen nannies were mistaken and believed freezing foods to kill bacteria and keeping the refrigerator between 45 and 65 degrees Fahrenheit were appropriate in keeping food safe. Similar findings were presented in a review on consumer food safety knowledge and behavior (32). 


\section{Nutrition Behaviors}

\section{Food and Snacks}

Research has shown that parents believed that childcare providers were at least as important, and possibly more important than family members in shaping healthy nutritional habits of young children (33). Nannies considered this to be true of their employers regarding foods and snacks. This notion is supported by the equality of responsibility between parents and nannies in shopping for and deciding on foods and snacks to serve the children.

Nearly half of nannies reported 'never' or 'rarely' bringing food from home; and 'always' or 'most of the time' ate the same foods served to the children. However, nannies between the ages of 55 and 64 were more likely to eat the same foods served to the children while those between 35 and 44 years were less likely to behave in this manner. Nannies displayed consistent behavioral patterns regarding the use of restaurants to feed themselves or the children. All but three nannies reported they ate with the children at least "sometimes." This was analogous to those who reported they did not skip meals or cleaned while the children ate. These are positive findings, as research suggests that preschool children are more likely to mimic the eating patterns of adult role models $(14,33)$. The quantities of nannies that display these behaviors exceed that of past studies, where few childcare staff ate the same foods or sat at the table where the children were eating $(13,14,33)$.

\section{Feeding Styles}

Initially noted as parenting styles, Diana Baumrind first introduced three prototypical descriptions; authoritative, authoritarian, and permissive, also recognized as indulgent (34). Further research by Maccoby and Martin led to the addition of one parenting style, uninvolved, for a total of four parenting styles (35). Food-related parenting styles, also recognized as feeding styles, mimicked parenting styles, however focused on behaviors during mealtimes. Childcare providers, much like parents, were thought to have an influence on children through nutrition 
behaviors such as modeling, instruction, or leaving children to their own devices. As so, nutrition behaviors were based on the four feeding styles, authoritative, authoritarian, indulgent, and uninvolved.

Contrary to the findings by Hughes et al, nannies displayed more authoritarian and indulgent forms of feeding than authoritative and uninvolved (16). Based on previous research, it is speculated that nannies that followed an authoritarian style of feeding may have expected children to follow strict rules and failure may have resulted in disapproval and punishment $(34,35)$. Authoritarians' ability to reason is futile and often physically struggle with children. Additionally, authoritarian feeding behaviors are based on external control, very one-sided, and rarely acknowledged the child $(34,35)$. Indulgent nannies were likely to have few demands and rarely disciplined the children in their care. Those that are indulgent have relatively low expectations of maturity and self-control $(34,35)$. In this case, this behavior may have resulted in allowing children to eat what they wanted when they wanted. Although indulgent nannies may have been nurturing and communicative, it is probable they took on the role of a friend rather than an authority figure.

Fewer nannies displayed authoritative forms of behavior. According to Baumrind, authoritative rules and guidelines were established in a democratic manner. Authoritative caretakers are responsive, listen to the children, and reason with children during meals $(16,36)$. If a child failed to meet expectations, for example eating a full plate of food, authoritative nannies were more likely to be nurturing and forgiving rather than punishing. Based on the characteristics of uninvolved caretakers, nannies that displayed this type of behavior may have had little responsiveness and communication with the children. It is more likely that these nannies worked to fulfill the child's basic needs, but generally detached themselves from the child during mealtime. In extreme cases, these caregivers may have even rejected or neglected the needs of the children during mealtime. 
Without an observation component to the study or comparable research on nannies and feeding styles, it is difficult to assess these outcomes. However, various factors may have contributed to the differences in feeding styles of nannies as compared to childcare staff in previous research. Prior studies focused on the feeding styles of Hispanic and African American caretakers. These findings were based on a sample primarily made up of White American and Caucasian nannies $(16,36)$. The home environment and fewer children to care for during mealtimes may have altered nannies' feeding behaviors. Additionally, the inability to observe nannies during mealtimes and solely rely on a self-reported questionnaire may have contributed to the divergence in feeding styles.

It is important to note that feeding styles have been associated with caregivers and the foods made available for the children to consume. Authoritarian behaviors likely made fruits and vegetables less available to children while indulgent feeding styles have been associated with eating more vegetables, dairy, full entrees, and starch $(16,36)$. However, the increases in these foods were likely due to the leniency towards total food consumption. These factors are especially important when trying to positively influence the eating habits of children.

\section{Beliefs - Nutritional Influence on Children}

The majority of nannies believed that parents or guardians had the most influence on the eating habits of children. Nonetheless, nannies believed they had high influence on the nutritional habits of children as well as the nutrition education the children received under their care. These beliefs were concurrent to the importance nannies placed on serving meals and snacks that they considered nutritious and children receiving appropriate nutrition education during early childhood years. Similarly, the majority of the nannies agreed that it is very important to assist children in maintaining a healthy weight and aiding those who are overweight in losing weight. These findings were in accordance to the beliefs of childcare providers in a previous study (12). 
The demographic shift in society, where more mothers are working and the development of children's eating behaviors has become the responsibility of caretakers, may have shaped this belief system for the nannies (33). However, if more nannies are displaying authoritarian behaviors, noted to decrease the consumption of fruits and vegetables, it is possible that nannies' reported behavior does not always support their belief; this was evident for caretakers in childcare facilities as well (14).

\section{Research Questions}

What is the average nutrition knowledge score obtained by the nannies?

Nannies' raw score was 24 out of 32 points resulting in $75 \%$ correct for nutrition knowledge.

Are nannies' feeding behaviors authoritarian, authoritative, indulgent, or uninvolved?

Nannies primarily displayed authoritarian or indulgent feeding styles. Opposite in nature, authoritarian behaviors were characterized as stringent, unresponsive, and likely physically struggled with children during mealtimes, while indulgent feeding styles were nurturing and communicative, but the lack of disciplinary skills allowed free-will during times of eating.

\section{Do nannies believe they have an influence on the children they mind?}

Nannies believed that the persons with the most influence on the eating habits of children were parents and guardians. However, nannies believed they had a somewhat high influence on the nutritional habits of the children and the nutrition education received under their care. Nannies agreed that is was very important for them to assist children in maintaining a healthy weight and aiding those who are overweight to lose weight.

\section{Limitations}

This research needs to be considered despite its limitations. The study was conducted with a small sample size of nannies that were primarily White/Caucasian women; therefore the external validity for in-home caregivers may be limited. Due to the qualitative nature of the study, 
there is potential for biased interpretation of the results as well as reactive effects among the participants. In the same respect, results were based on self-reported data and lacked an observational component for comparison. These factors are of particular importance when assessing behaviors and beliefs because many times respondents will not accurately describe how they actually feel or do, especially if the behavior or belief is contrary to generally accepted norms.

A sample of nannies was difficult to obtain. Foremost, scientific research on nannies is virtually non-existent; therefore following the guidelines and patterns of previous research was unattainable. Furthermore, the International Nanny Association, National Association of Nanny Care, and Association of Premier Nanny Agencies apply a very strict privacy policy for their members. As such, the researcher was not privy to personal information of potential participants and relied solely on the contribution of those in communication with the researcher. The inability to decipher the exact size and sample frame of the population hindered the calculation of an accurate response rate.

Other possibilities may have impacted the low response count. The subject of nutrition may not be of concern to working nannies, as it is still considered a new topic of interest in the nanny profession. Communication between nannies, agencies, and large organizations like the NA primarily exist through newsletters, online communities, and social networking sites. While it may be applicable to establish a sampling frame based on number of participants or published number of members over a given period of time, the vacillation of communication via the web may be sporadic and unreliable (37). As with most research populations, there are undoubtedly some individuals who are more willing to complete surveys, especially among online community members. In an age where online advertisement and surveys are a constant and many times considered "spam", people may have been desensitized to worthwhile requests to participate in a survey (37). The lack of incentives too may have dissuaded potential participants. 


\section{Recommendations}

Recommendations to advance nannies' nutrition knowledge and awareness are many. Currently, the International Nanny Association (INA) leads the industry in resources and credentialing for in-home caregivers. It would be advantageous to partner with the INA and present insight on the nutrition portions of the credentialing exams as well as offer courses for professional development in adult and pediatric nutrition. It would be ideal for nanny and governess schools to require a more in depth nutrition component to the curriculum they offer. The American Dietetic Association could offer an extension of their Benchmarks for Nutrition Programs in Child Care Settings to include guidelines specific to caregivers who provide childcare in a home setting (38). Upon doing so, appropriate nutrition education and intervention strategies may be developed to increase proper feeding and eating habits among nannies and children.

\section{Future Research}

Future research opportunities might include an observational component in addition to self-reported surveys and questionnaires. One might focus and expand on one aspect of nanny care, for example only knowledge, behaviors, or beliefs, rather than combining all in one study. While it is quite apparent that nannies believe they have an influence on children, it is warranted to study behaviors they intentionally put into action for the purpose of influencing a child. Examining the characteristics and personalities of children under nanny care may provide further insight on the effects of specific feeding styles.

\section{Conclusion}

Although a small sample, these nannies revealed they had an average knowledge of nutrition and food and exceeded the overall scores of caretakers in childcare centers, teachers, and nurses. Nannies believed they influenced the nutritional habits of children, including the nutrition education children receive under their care. While this is promising, nannies predominantly 
displayed feeding styles that would tend to result in poor nutritional habits for the children. Authoritarian behavior is characterized as stringent and inconsiderate of a child's nutritional needs and indulgent feeding styles, while typified as nurturing, are described as too flexible during mealtimes and may unintentionally promote overeating. Overall, these findings indicated a need for food and nutrition education and training among nannies. Not only is it important for nannies to attend nutrition education sessions, it is vital for nannies to gain knowledge on how the various feeding styles affect a child's nutrition. Although nannies are a population with little research, they are a growing trend in childcare. Nannies and researchers alike must be knowledgeable and cognizant of the issues surrounding in-home childcare as popularity continues to rise. 
Table 1. Demographic characteristics of respondents who completed a national survey: Knowledge, behaviors, and beliefs of nannies on nutrition and children $(n=83)$

\begin{tabular}{|c|c|c|c|}
\hline Demographics & & $\mathrm{n}$ & $\%$ \\
\hline \multirow[t]{6}{*}{ Age } & $18-24$ years & 8 & $9.6 \%$ \\
\hline & $25-34$ years & 29 & $34.9 \%$ \\
\hline & $35-44$ years & 24 & $28.9 \%$ \\
\hline & $45-54$ years & 16 & $19.3 \%$ \\
\hline & $55-64$ years & 6 & $7.2 \%$ \\
\hline & 65 years and older & 0 & $0 \%$ \\
\hline \multirow[t]{2}{*}{ Gender } & Women & 83 & $100 \%$ \\
\hline & Men & & $0 \%$ \\
\hline \multirow[t]{6}{*}{ Education Level } & Some College or Nanny Certificate & 10 & $12 \%$ \\
\hline & High School & 10 & $12 \%$ \\
\hline & Vocational & 19 & $22.9 \%$ \\
\hline & Associate's Degree & 21 & $25.3 \%$ \\
\hline & Bachelor's Degree & 19 & $22.9 \%$ \\
\hline & Master's Degree & 4 & $4.8 \%$ \\
\hline \multirow[t]{4}{*}{ Ethnicity } & Black/African American & 3 & $3.6 \%$ \\
\hline & Hispanic/Latino & 1 & $1.2 \%$ \\
\hline & White American/Caucasian & 78 & $94 \%$ \\
\hline & Other & 1 & $1.2 \%$ \\
\hline Employment & Years in the Childcare Industry & & \\
\hline \multirow[t]{6}{*}{ History } & Less than one year & 0 & $0 \%$ \\
\hline & $1-5$ years & 16 & $19.3 \%$ \\
\hline & $6-10$ years & 13 & $15.7 \%$ \\
\hline & $11-20$ years & 34 & $41 \%$ \\
\hline & $21-30$ years & 19 & $22.9 \%$ \\
\hline & 31 years or more & 1 & $1.2 \%$ \\
\hline Employment & Full Time $(40 \mathrm{hrs} \leq$ per wk) & 60 & $73.2 \%$ \\
\hline \multirow[t]{8}{*}{ Status } & Part Time $(<40$ hrs per wk) & 12 & $14.6 \%$ \\
\hline & $\begin{array}{l}\text { Not currently working as a nanny, but } \\
\text { looking for hire }\end{array}$ & 5 & $6.1 \%$ \\
\hline & $\begin{array}{l}\text { Not currently working as a nanny and } \\
\text { not looking for hire }\end{array}$ & 5 & $6.1 \%$ \\
\hline & No Answer & 1 & $1.2 \%$ \\
\hline & Live-in & 21 & $25.3 \%$ \\
\hline & Non Live-in & 55 & $66.3 \%$ \\
\hline & Both & 5 & $6.0 \%$ \\
\hline & No Answer & 2 & $2.4 \%$ \\
\hline
\end{tabular}




\begin{tabular}{|c|c|c|c|}
\hline Work & Number of employer(s): & & \\
\hline \multirow{15}{*}{ Environment } & 1 & 64 & $77.1 \%$ \\
\hline & 2 & 8 & $9.6 \%$ \\
\hline & 3 & 4 & $4.8 \%$ \\
\hline & 4 or more & 2 & $2.4 \%$ \\
\hline & No Answer & 5 & $6.0 \%$ \\
\hline & Yearly income of employer: & & \\
\hline & Less than $\$ 100,000$ & 6 & $7.2 \%$ \\
\hline & More than $\$ 100,000$ & 51 & $61.4 \%$ \\
\hline & Not Sure & 22 & $26.5 \%$ \\
\hline & Both & 1 & $1.2 \%$ \\
\hline & No Answer & 3 & $3.6 \%$ \\
\hline & Single Parent Household & 3 & $3.6 \%$ \\
\hline & Dual Parent Household & 76 & $91.6 \%$ \\
\hline & Both & 1 & $1.2 \%$ \\
\hline & No Answer & 3 & $3.6 \%$ \\
\hline \multirow[t]{20}{*}{ Children } & Number of children cared for: & & \\
\hline & 1 & 17 & $20.5 \%$ \\
\hline & 2 & 35 & $42.2 \%$ \\
\hline & 3 & 18 & $21.7 \%$ \\
\hline & 4 & 5 & $6.0 \%$ \\
\hline & 5 & 1 & $1.2 \%$ \\
\hline & 6 or more & 4 & $4.8 \%$ \\
\hline & No Answer & 3 & $3.6 \%$ \\
\hline & Age of children care for*: & & \\
\hline & Infants (birth-12 months) & 27 & $33.8 \%$ \\
\hline & Toddlers $(1-2$ years old $)$ & 29 & $36.3 \%$ \\
\hline & Pre-School (3-4 years old) & 35 & $43.8 \%$ \\
\hline & School-Age (5-7 years old) & 28 & $35.0 \%$ \\
\hline & Adolescents (8-14 years old) & 26 & $32.6 \%$ \\
\hline & 15 years and older & 8 & $10.0 \%$ \\
\hline & No Answer & 3 & $3.6 \%$ \\
\hline & Do you have children of your own? & & \\
\hline & Yes & 16 & $19.5 \%$ \\
\hline & No & 66 & $80.5 \%$ \\
\hline & No Answer & 1 & $1.2 \%$ \\
\hline
\end{tabular}




\begin{tabular}{llrr} 
Region $^{\text {a }}$ & Live: & & \\
West & Midwest & 23 & $27.7 \%$ \\
Northeast & 14 & $16.9 \%$ \\
South & 17 & $20.5 \%$ \\
Canada/Europe & 26 & $31.3 \%$ \\
No Answer & 2 & $2.4 \%$ \\
Work: & 1 & $1.2 \%$ \\
West & 22 & $26.5 \%$ \\
Midwest & 14 & $16.9 \%$ \\
Northeast & 17 & $20.5 \%$ \\
South & 25 & $30.1 \%$ \\
Canada/Europe & 1 & $1.2 \%$ \\
No Answer & 4 & $4.8 \%$ \\
\hline
\end{tabular}

${ }^{a}$ Based on Census Region and Divisions of the United States

* Multiple responses 


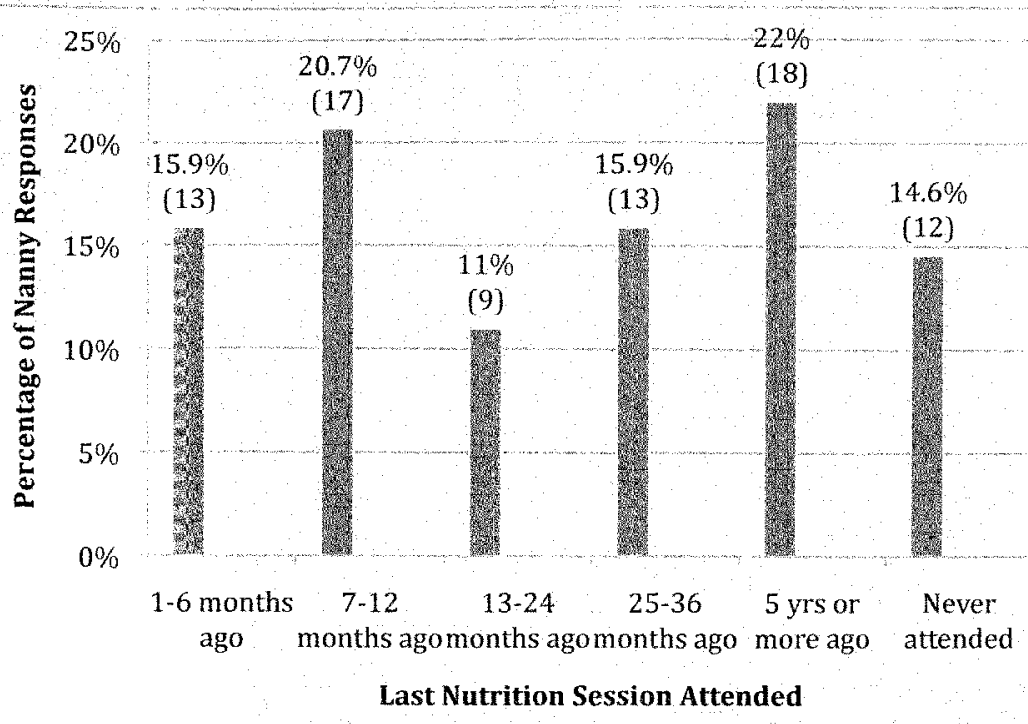

Figure 1. The last nutrition workshop, class, lecture, and/or information session attended by the nannies $(n=83)$

Table 2. Sources of nutrition information that nannies access ${ }^{\mathrm{a}}$

\begin{tabular}{|l|c|c|}
\hline Source & $\mathrm{n}$ & $\%$ \\
\hline Health Care Professional & 64 & 77.1 \\
\hline $\begin{array}{l}\text { Print Media (Newspapers, Books, Magazines, } \\
\text { Newsletters, Flyers) }\end{array}$ & 75 & 90.4 \\
\hline Non-Print Media (Television, Radio, Internet) & 56 & 67.5 \\
\hline Relatives & 22 & 26.5 \\
\hline Friends & 38 & 45.8 \\
\hline Food Labels & 72 & 86.7 \\
\hline Nutrition/Supplement Store & 26 & 31.3 \\
\hline $\begin{array}{l}\text { Conference/Workshop/ } \\
\text { Class }\end{array}$ & 5 & 6.0 \\
\hline
\end{tabular}

${ }^{a}$ multiple responses 
Table 3. Total points of nutrition knowledge scores

\begin{tabular}{|l|c|c|}
\hline \multicolumn{1}{|c|}{$\begin{array}{c}\text { Percent } \\
\%\end{array}$} & $\begin{array}{c}\text { Points } \\
(\mathbf{M}=\mathbf{2 4})\end{array}$ & n \\
\hline 0 & 0 & 13 \\
\hline $100-90$ & $29-30$ & 5 \\
\hline $89-80$ & $26-28$ & 19 \\
\hline $79-70$ & $23-25$ & 26 \\
\hline $69-60$ & $20-22$ & 13 \\
\hline 59 and below & $19-14$ & 7 \\
\hline Total & 32 & 83 \\
\hline
\end{tabular}

Table 4. Nanny responses when asked to classify item as food or nutrient

\begin{tabular}{|l|cc|cc|cc|}
\hline Item & \multicolumn{2}{|c|}{ Food } & \multicolumn{2}{|c|}{ Not Sure } & \multicolumn{2}{c|}{ Nutrient } \\
& $\mathrm{n}$ & $\%$ & $\mathrm{n}$ & $\%$ & $\mathrm{n}$ & $\%$ \\
\hline & & & & & & \\
\hline Meat & 65 & 92.9 & 0 & 0 & 5 & 7.1 \\
\hline Protein & 4 & 5.7 & 0 & 0 & 66 & 94.3 \\
\hline Calcium & 0 & 0 & 0 & 0 & 70 & 100 \\
\hline Milk & 62 & 89.9 & 0 & 0 & 7 & 10.1 \\
\hline Carbohydrate & 11 & 15.7 & 1 & 1.4 & 58 & 82.9 \\
\hline Eggs & 66 & 94.3 & 0 & 0 & 4 & 5.7 \\
\hline Sodium & 5 & 7.2 & 4 & 5.8 & 60 & 87 \\
\hline Niacin & 1 & 1.4 & 5 & 7.1 & 64 & 91.4 \\
\hline Fat & 9 & 12.9 & 7 & 10 & 54 & 77.1 \\
\hline Iron & 0 & 0 & 0 & 0 & 70 & 100 \\
\hline
\end{tabular}

Table 5. Nanny responses when asked to identify the correct pairs of food and nutrient

\begin{tabular}{|l|cc|cc|cc|}
\hline Item & \multicolumn{2}{|c|}{$\begin{array}{c}\text { Yes, Paired } \\
\text { Correctly }\end{array}$} & \multicolumn{2}{|c|}{ Not Sure } & \multicolumn{2}{c|}{$\begin{array}{c}\text { No, Not Paired } \\
\text { Correctly }\end{array}$} \\
\hline & $\mathrm{n}$ & $\%$ & $\mathrm{n}$ & $\%$ & $\mathrm{n}$ & $\%$ \\
\hline Orange Soda and Vitamin C & 9 & 13 & 3 & 4.3 & 57 & 82.6 \\
\hline Low-Fat Milk and Calcium & 67 & 95.7 & 0 & 0 & 3 & 4.3 \\
\hline Sweet Potato and Vitamin A & 55 & 78.6 & 14 & 20 & 1 & 1.4 \\
\hline Ground Beef and Vitamin D & 10 & 14.5 & 17 & 24.6 & 42 & 60.9 \\
\hline $\begin{array}{l}\text { Whole Wheat Bread and Vitamin } \\
\text { B12 }\end{array}$ & 40 & 57.1 & 20 & 28.6 & 10 & 14.3 \\
\hline
\end{tabular}


Table 6. Nanny responses to the question: A kilocalorie (calorie) is a measure of?

\begin{tabular}{|l|c|c|}
\hline Definition & $\mathrm{n}$ & $\%$ \\
\hline The amount of heat required to digest the food we eat & 16 & 23.5 \\
\hline The energy value of food & 37 & 54.4 \\
\hline Fat, vitamin, carbohydrate content of food & 4 & 5.9 \\
\hline Carbohydrate, protein, fat content of food & 11 & 16.2 \\
\hline
\end{tabular}

Table 7. Nanny responses when asked to identify the TRUE statement

\begin{tabular}{|l|c|c|}
\hline Statement & $\mathrm{n}$ & $\%$ \\
\hline $\begin{array}{l}\text { Even if you are on a weight reduction diet, it does not } \\
\text { matter how much protein you eat since protein dies } \\
\text { not have a calories }\end{array}$ & 1 & 1.4 \\
\hline $\begin{array}{l}\text { Eating half of a grapefruit after each meal will help } \\
\text { you burn away excess calories }\end{array}$ & 3 & 4.3 \\
\hline $\begin{array}{l}\text { Calorie intake in excess of an individual's } \\
\text { requirements is stored in the body as fat }\end{array}$ & 66 & 94.3 \\
\hline Most obese individuals have glandular abnormalities & 0 & 0 \\
\hline
\end{tabular}

Table 8. Nanny responses when asked to identify which practices make food safe

\begin{tabular}{|l|cc|cc|cc|}
\hline Item & \multicolumn{2}{|c|}{ Yes } & \multicolumn{2}{|c|}{ Not Sure } & \multicolumn{2}{c|}{ No } \\
& $\mathrm{n}$ & $\%$ & $\mathrm{n}$ & $\%$ & $\mathrm{n}$ & $\%$ \\
\hline & & & & & & \\
\hline Hand-washing & 67 & 95.7 & 2 & 2.9 & 1 & 1.4 \\
\hline $\begin{array}{l}\text { Using the same cutting board for } \\
\text { raw poultry and vegetables }\end{array}$ & 0 & 0 & 0 & 0 & 69 & 100 \\
\hline Thawing frozen chicken in the sink & 5 & 7.2 & 4 & 5.8 & 60 & 87 \\
\hline Freezing foods to kill bacteria & 17 & 24.6 & 11 & 15.9 & 41 & 59.4 \\
\hline $\begin{array}{l}\text { Keeping the refrigerator between 45 } \\
\text { and 65 degrees Fahrenheit }\end{array}$ & 17 & 25.4 & 23 & 17.9 & 38 & 56.7 \\
\hline
\end{tabular}




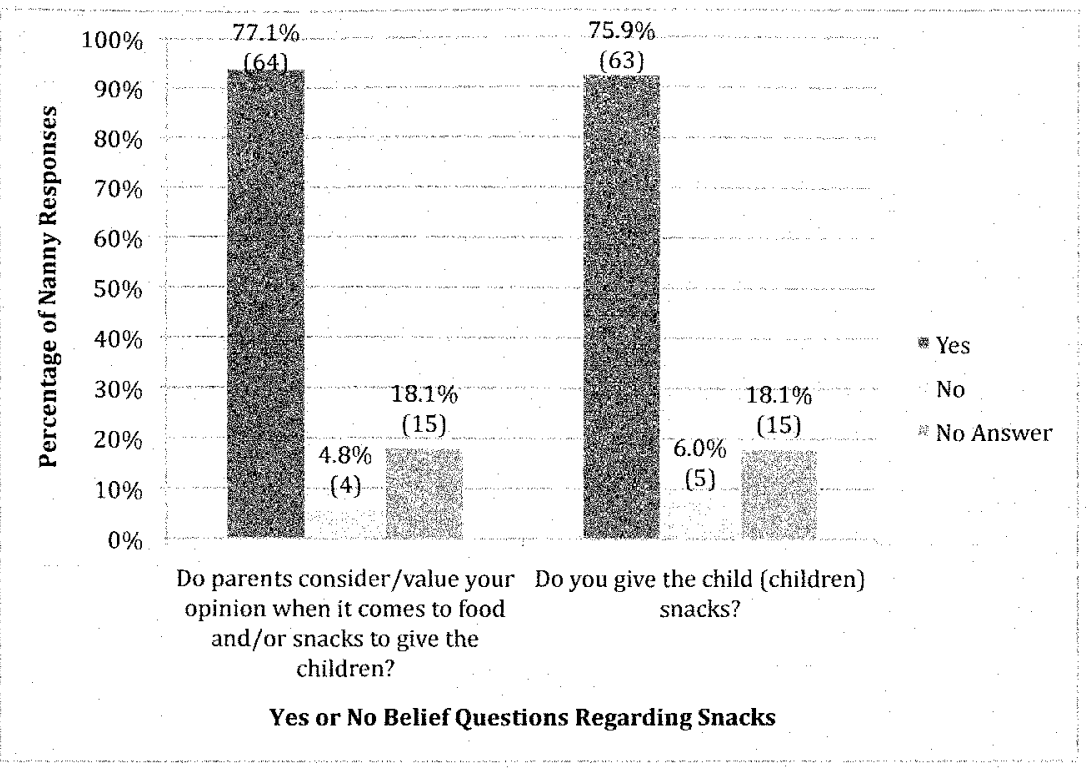

Figure 2. Yes or no belief questions answered by the nannies 


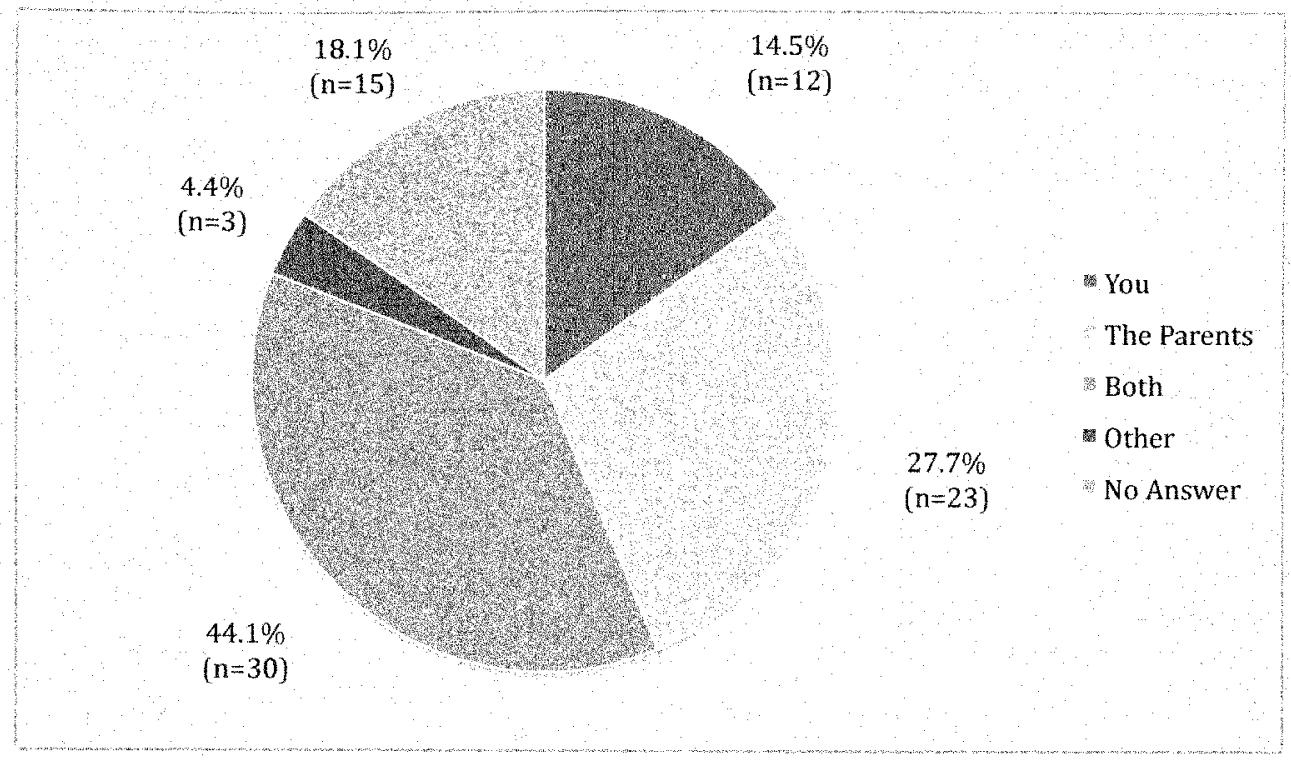

Figure 3. Nanny responses to the question, "Who shops for the food and/or snacks that the children you care for eat?" $(\mathrm{n}=83)$

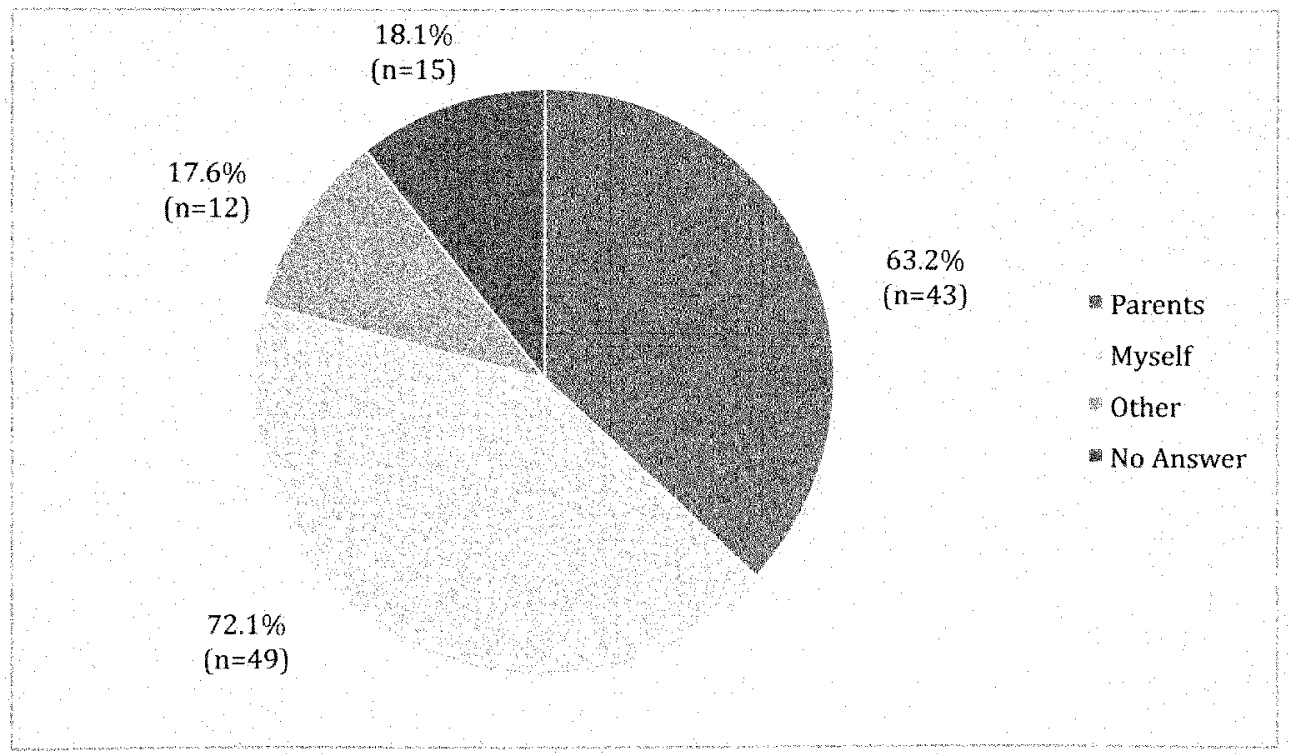

Figure 4. Nanny responses to the question, "Who decides what food and/or snack choices the children have to eat? $(n=83)^{\text {a }}$

${ }^{a}$ multiple responses 
Table 9. Nanny responses when asked to describe the frequency of behaviors when eating

\begin{tabular}{|c|c|c|c|c|c|c|c|c|c|c|}
\hline \multirow[t]{2}{*}{$\begin{array}{l}\text { Feeding } \\
\text { Behavior }\end{array}$} & \multicolumn{2}{|c|}{ Never } & \multicolumn{2}{|c|}{ Rarely } & \multicolumn{2}{|c|}{ Sometimes } & \multicolumn{2}{|c|}{$\begin{array}{c}\text { Most of the } \\
\text { Time }\end{array}$} & \multicolumn{2}{|c|}{ Always } \\
\hline & $\mathrm{n}$ & $\%$ & $\mathrm{n}$ & $\%$ & $\mathrm{n}$ & $\%$ & $\mathrm{n}$ & & $\mathrm{n}$ & $\%$ \\
\hline $\begin{array}{l}\text { I eat the same } \\
\text { foods served } \\
\text { to the } \\
\text { children. }\end{array}$ & 3 & 4.5 & 6 & 9 & 23 & 34.3 & 26 & 38.8 & 9 & 13.4 \\
\hline $\begin{array}{l}\text { I bring food } \\
\text { from home. }\end{array}$ & 19 & 27.9 & 14 & 20.6 & 14 & 20.6 & 13 & 19.1 & 8 & 11.8 \\
\hline $\begin{array}{l}\text { I order from a } \\
\text { restaurant for } \\
\text { pick-up or } \\
\text { delivery to } \\
\text { feed myself. }\end{array}$ & 30 & 44.1 & 24 & 35.3 & 13 & 19.1 & 1 & 1.5 & 0 & 0 \\
\hline $\begin{array}{l}\text { I skip most } \\
\text { meals while } \\
\text { caring for } \\
\text { children. }\end{array}$ & 35 & 52.2 & 17 & 25.4 & 14 & 20.9 & 1 & 1.5 & 0 & 0 \\
\hline $\begin{array}{l}\text { I eat with the } \\
\text { children. }\end{array}$ & 1 & 1.5 & 2 & 3 & 21 & 31.8 & 21 & 31.8 & 21 & 31.8 \\
\hline $\begin{array}{l}\text { I clean while } \\
\text { the children } \\
\text { eat. }\end{array}$ & 21 & 31.8 & 23 & 34.8 & 19 & 28.8 & 3 & 4.5 & 0 & 0 \\
\hline $\begin{array}{l}\text { I order from a } \\
\text { restaurant for } \\
\text { pick-up or } \\
\text { delivery to } \\
\text { feed the } \\
\text { children. }\end{array}$ & 28 & 41.2 & 29 & 42.6 & 11 & 16.2 & 0 & 0 & 0 & 0 \\
\hline $\begin{array}{l}\text { I take the } \\
\text { children to } \\
\text { eat at a fast- } \\
\text { food or other } \\
\text { restaurants. }\end{array}$ & 14 & 20.6 & 33 & 48.5 & 20 & 29.4 & 1 & 1.5 & 0 & 0 \\
\hline
\end{tabular}


Table 10. Nanny responses to feeding behaviors characterized by quotes

\begin{tabular}{|c|c|c|c|c|c|c|c|c|c|c|}
\hline \multirow[t]{2}{*}{$\begin{array}{l}\text { Feeding } \\
\text { Behavior }\end{array}$} & \multicolumn{2}{|c|}{ Never } & \multicolumn{2}{|c|}{ Rarely } & \multicolumn{2}{|c|}{ Sometimes } & \multicolumn{2}{|c|}{$\begin{array}{c}\text { Most of the } \\
\text { Time }\end{array}$} & \multicolumn{2}{|c|}{ Always } \\
\hline & $n$ & $\%$ & $\mathrm{n}$ & $\%$ & $n$ & $\%$ & $\mathrm{n}$ & $\%$ & $n$ & $\%$ \\
\hline $\begin{array}{l}\text { "If you finish } \\
\text { your } \\
\text { vegetables } \\
\text { you will get } \\
\text { ice cream." }\end{array}$ & 40 & 57.1 & 20 & 28.6 & 9 & 12.9 & 1 & 1.4 & 0 & 0 \\
\hline $\begin{array}{l}\text { "If you eat } \\
\text { your beans, } \\
\text { we can play } \\
\text { after dinner." }\end{array}$ & 50 & 71.4 & 7 & 10 & 9 & 12.9 & 4 & 5.7 & 0 & 0 \\
\hline $\begin{array}{l}\text { "What a good } \\
\text { boy! You're } \\
\text { eating your } \\
\text { vegetables." }\end{array}$ & 11 & 5.9 & 8 & 11.6 & 22 & 31.9 & 18 & 26.1 & 10 & 14.5 \\
\hline $\begin{array}{l}\text { "Eat your } \\
\text { dinner, it is } \\
\text { getting cold." }\end{array}$ & 26 & 37.7 & 21 & 30.4 & 13 & 18.8 & 5 & 7.2 & 4 & 5.8 \\
\hline $\begin{array}{l}\text { "Hurry up } \\
\text { and eat your } \\
\text { food." }\end{array}$ & 34 & 48.6 & 17 & 24.3 & 16 & 22.9 & 3 & 4.3 & 0 & 0 \\
\hline $\begin{array}{l}\text { "Milk is good } \\
\text { for your } \\
\text { health } \\
\text { because it } \\
\text { will make } \\
\text { you strong." }\end{array}$ & 12 & 17.1 & 8 & 11.4 & 19 & 27.1 & 22 & 31.4 & 9 & 12.9 \\
\hline $\begin{array}{l}\text { "If you don't } \\
\text { finish you } \\
\text { meal, there } \\
\text { will be no } \\
\text { play time } \\
\text { after dinner." }\end{array}$ & 54 & 77.1 & 10 & 14.3 & 5 & 7.1 & 1 & 1.4 & 0 & 0 \\
\hline $\begin{array}{l}\text { "If you don't } \\
\text { finish your } \\
\text { vegetables, } \\
\text { you won't get } \\
\text { candy." }\end{array}$ & 57 & 81.4 & 9 & 12.9 & 4 & 5.7 & 0 & 0 & 0 & 0 \\
\hline $\begin{array}{l}\text { "You need to } \\
\text { eat your } \\
\text { fruit." }\end{array}$ & 5 & 7.2 & 13 & 18.8 & 22 & 31.9 & 23 & 33.3 & 6 & 8.7 \\
\hline
\end{tabular}


Table 11. Nanny responses to feeding behaviors characterized by statements

\begin{tabular}{|c|c|c|c|c|c|c|c|c|c|c|}
\hline \multirow[t]{2}{*}{$\begin{array}{l}\text { Feeding } \\
\text { Behavior }\end{array}$} & \multicolumn{2}{|c|}{ Never } & \multicolumn{2}{|c|}{ Rarely } & \multicolumn{2}{|c|}{ Sometimes } & \multicolumn{2}{|c|}{$\begin{array}{c}\text { Most of the } \\
\text { Time }\end{array}$} & \multicolumn{2}{|c|}{ Always } \\
\hline & $\mathrm{n}$ & $\%$ & $\mathrm{n}$ & $\%$ & $n$ & $\%$ & $\mathrm{n}$ & $\%$ & $\mathrm{n}$ & $\%$ \\
\hline $\begin{array}{l}\text { Arranges food } \\
\text { to make it } \\
\text { interesting (for } \\
\text { example, } \\
\text { making smiley } \\
\text { faces on } \\
\text { pancakes). }\end{array}$ & 6 & 8.6 & 9 & 12.9 & 34 & 48.6 & 15 & 21.4 & 6 & 8.6 \\
\hline $\begin{array}{l}\text { Asks the child } \\
\text { questions about } \\
\text { the food. }\end{array}$ & 2 & 2.9 & 7 & 10 & 31 & 44.3 & 25 & 35.7 & 5 & 7.1 \\
\hline $\begin{array}{l}\text { Telis the child } \\
\text { to eat at least a } \\
\text { little bit of food } \\
\text { on his or her } \\
\text { plate. }\end{array}$ & 4 & 5.8 & 2 & 2.9 & 25 & 36.2 & 27 & 39 & 11 & 15.9 \\
\hline $\begin{array}{l}\text { Says something } \\
\text { to show } \\
\text { disapproval of } \\
\text { the child for not } \\
\text { eating the meal }\end{array}$ & 22 & 31.9 & 30 & 43.5 & 14 & 20.3 & 3 & 4.3 & 0 & 0 \\
\hline $\begin{array}{l}\text { Allows the } \\
\text { child to choose } \\
\text { the foods he or } \\
\text { she wants to eat } \\
\text { for the meal } \\
\text { from foods } \\
\text { already } \\
\text { prepared. }\end{array}$ & 5 & 7.1 & 8 & 11.4 & 22 & 31.4 & 20 & 28.6 & 15 & 21.4 \\
\hline $\begin{array}{l}\text { Says something } \\
\text { positive about } \\
\text { the food the } \\
\text { child is eating } \\
\text { during the meal. }\end{array}$ & 1 & 1.4 & 1 & 1.4 & 12 & 17.1 & 31 & 44.3 & 25 & 35.7 \\
\hline $\begin{array}{l}\text { Spoon-feeds the } \\
\text { child to get him } \\
\text { or her to eat the } \\
\text { meal. }\end{array}$ & 26 & 37.1 & 27 & 38.6 & 11 & 15.7 & 5 & 7.1 & 1 & 1.4 \\
\hline $\begin{array}{l}\text { Helps the child } \\
\text { to eat dinner } \\
\text { (for example, } \\
\text { cuts the food } \\
\text { into smaller } \\
\text { pieces). }\end{array}$ & 4 & 5.8 & 4 & 5.8 & 22 & 31.9 & 25 & 36.2 & 14 & 20.3 \\
\hline $\begin{array}{l}\text { Restrains a } \\
\text { child reluctant } \\
\text { to eat }\end{array}$ & 62 & 88.6 & 7 & 10 & 1 & 1.4 & 0 & 0 & 0 & 0 \\
\hline $\begin{array}{l}\text { Begs the child } \\
\text { to eat dinner }\end{array}$ & 60 & 85.7 & 7 & 10 & 3 & 4.3 & 0 & 0 & 0 & 0 \\
\hline
\end{tabular}




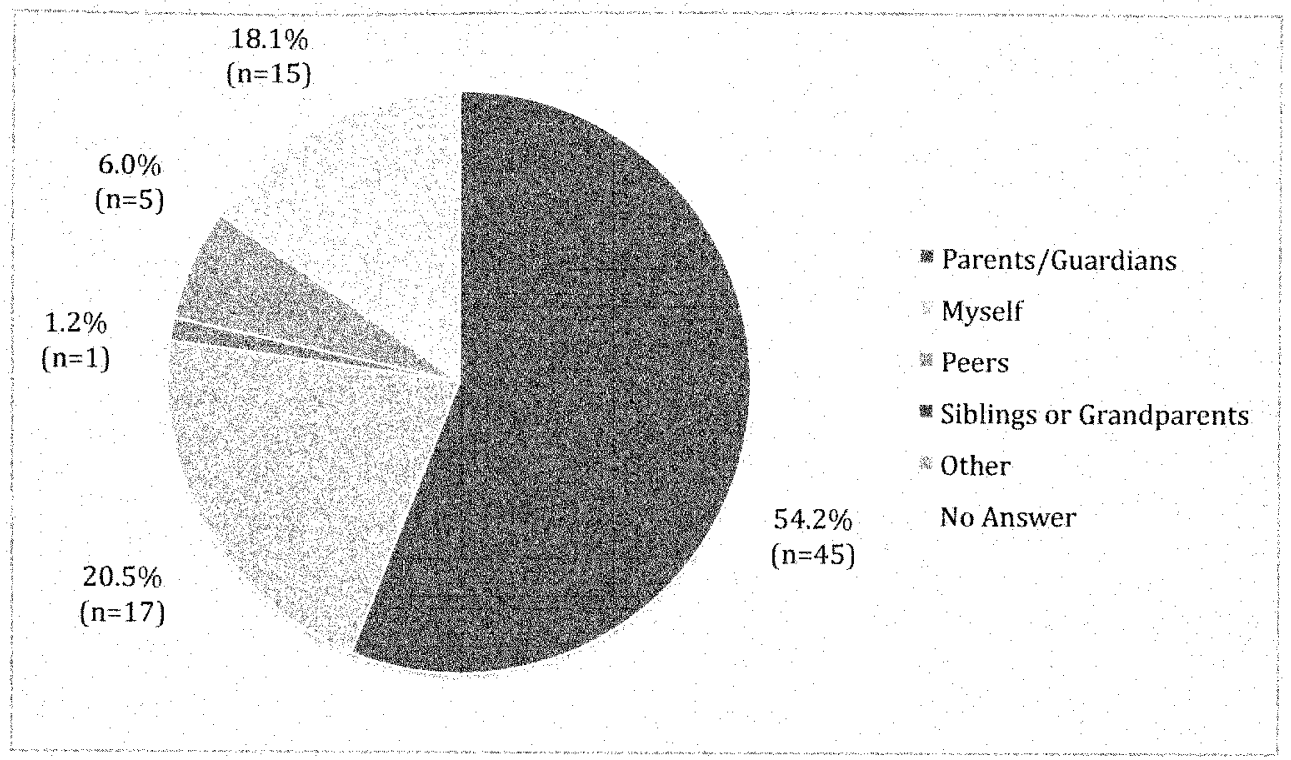

Figure 5. Nanny responses to the statement, "The person(s) who has/have the greatest influence on eating habits of the children you care for is/are:" $(n=83)$

Table 12. Nanny responses when asked to describe their level of influence

\begin{tabular}{|c|c|c|c|c|c|c|c|c|c|c|}
\hline \multirow{2}{*}{ Influence on: } & \multicolumn{2}{|c|}{$\begin{array}{l}\text { Very High } \\
\text { Influence }\end{array}$} & \multicolumn{2}{|c|}{$\begin{array}{c}\text { Somewhat } \\
\text { High } \\
\text { Influence }\end{array}$} & \multicolumn{2}{|c|}{$\begin{array}{l}\text { Moderate } \\
\text { Influence }\end{array}$} & \multicolumn{2}{|c|}{$\begin{array}{c}\text { Somewhat } \\
\text { Low } \\
\text { Influence }\end{array}$} & \multicolumn{2}{|c|}{$\begin{array}{c}\text { No } \\
\text { Influence }\end{array}$} \\
\hline & $n$ & $\%$ & $\mathrm{n}$ & $\%$ & $n$ & $\%$ & $n$ & $\%$ & $n$ & $\%$ \\
\hline $\begin{array}{l}\text { The } \\
\text { nutritional } \\
\text { habits of the } \\
\text { children in } \\
\text { your care. }\end{array}$ & 26 & 38.2 & 28 & 41.2 & 11 & 16.2 & 2 & 2.9 & 1 & 1.5 \\
\hline $\begin{array}{l}\text { The nutrition } \\
\text { education that } \\
\text { the children } \\
\text { in your care } \\
\text { receive. }\end{array}$ & 26 & 38.2 & 25 & 36.8 & 13 & 19.1 & 2 & 2.9 & 2 & 2.9 \\
\hline
\end{tabular}


Table 13. Nanny responses when asked to rate the level of importance

\begin{tabular}{|c|c|c|c|c|c|c|c|c|c|c|}
\hline & \multicolumn{2}{|c|}{$\begin{array}{c}\text { Very } \\
\text { Important }\end{array}$} & \multicolumn{2}{|c|}{$\begin{array}{l}\text { Somewhat } \\
\text { Important }\end{array}$} & \multicolumn{2}{|c|}{ Neutral } & \multicolumn{2}{|c|}{$\begin{array}{c}\text { Somewhat } \\
\text { Unimportant }\end{array}$} & \multicolumn{2}{|c|}{$\begin{array}{c}\text { Very } \\
\text { Unimportant }\end{array}$} \\
\hline & & & & $\%$ & $n$ & $\%$ & & $\%$ & & $\%$ \\
\hline $\begin{array}{l}\text { Assisting the } \\
\text { children in } \\
\text { maintaining a } \\
\text { healthy weight. }\end{array}$ & 41 & 60.3 & 14 & 20.6 & 11 & 16.2 & 1 & 1.5 & 1 & 1.5 \\
\hline $\begin{array}{l}\text { Assisting the } \\
\text { children who } \\
\text { are overweight } \\
\text { in losing } \\
\text { weight. }\end{array}$ & 25 & 37.3 & 18 & 26.9 & 22 & 32.8 & 2 & 3 & 0 & 0 \\
\hline $\begin{array}{l}\text { Serving the } \\
\text { children meals } \\
\text { and snacks that } \\
\text { you would } \\
\text { consider } \\
\text { nutritious. }\end{array}$ & 62 & 92.5 & 2 & 3 & 0 & 0 & 1 & 1.5 & 2 & 3 \\
\hline $\begin{array}{l}\text { Children } \\
\text { receiving } \\
\text { appropriate } \\
\text { nutrition } \\
\text { education } \\
\text { during early } \\
\text { childhood } \\
\text { years. }\end{array}$ & 49 & 72.1 & 13 & 19.1 & 3 & 4.4 & 1 & 1.5 & 2 & 3 \\
\hline
\end{tabular}




\section{LIST OF REFERENCES}

1. Patrick $\mathrm{H}$, Nicklas TA. A review of family and social determinants of children's eating patterns and diet quality. J Am Coll Nutr. 2005;24(2):83-92.

2. Crockett SJ, Sims, LS. Environmental influences on children's eating. $J$ Nutr Educ. 1995;27(5): 235-249.

3. Story M, Neumark-Sztainer, French S. Individual and environmental influences on adolescent eating behaviors. I Am Diet Assoc. 2002;102(3):S40-S51.

4. Van der Horst K, Oenema A, Ferreira I, Wendel-Vos W, Giskes K, Van Lenthe F, Brug J. A systematic review of environmental correlates of obesity-related dietary behaviors in youth. Health Educ Res. 2007;22(2):203-226.

5. Gordon RA, Chase-Lansdale L. Availability of child care in the United States: A description and analysis of data sources. Demography. 2001;38(2):299-316.

6. Employment characteristics of families summary. March 27, 2010. Cited 2010 August 1. Available from http://www.bls.gov/news.release/famee.nr0.htm.

7. Hofferth SL. Child care in the United States today. Future Child. 1996;6(2):41-61.

8. Occupational outlook handbook, 2010-11 editions: Childcare workers. (n.d.). Available from http://www.bls.gov/oco/ocos170.htm. Accessed August 12010.

9. Story M, Kaphingst KM, French $\mathrm{S}$. The role of child care settings in obesity prevention. Future Child. 2006;16:143-168.

10. Bhana $\mathrm{K}$, Bhana A. Colour concepts attitudes among Indian preschool childiren as a function of black nannies. J Behav Sci. 1975;2(3):11 15-120.

11. Briley ME, Jastrow S, Vickers J, Roberts-Gray C. Dietary intake at child-care centers and away: are parents and care providers working as partners or at cross-purposes? J Am Diet Assoc. 1999;99:950-954.

12. Moore H, Nelson P, Marshall J, Cooper M, Zambas H. Brewster K, Atkin K. Laying foundations for health: Food provision for under $5 \mathrm{~s}$ in day care. Appetite. 2005;44:207213.

13. Sigman-Grant M, Christiansen E, Branen L, Fletcher J, Johnson SL. About feeding children: Mealtimes in child-care centers in four western states. I Am Diet Assoc. 2008; 108:340-346.

14. Nelms-Nahikian M. Influential factors of caregiver behavior at mealtime: A study of 24 childcare programs. $J$ Am Diet Assoc. 1997;97:505-509.

15. Briley ME, Roberts-Gray C, Simpson D. Identification of factors that influence the menu at child care centers: a grounded theory approach. I Am Diet Assoc. 1994;94:276-281. 
16. Hughes SO, Patrick H, Power TG, Fisher JO, Anderson CB, Nicklas TA. The impact of child care providers' feeding on children's food consumption. J Dev Behov Pediatr. $2007 ; 28: 1-8$.

17. Evans FR. A survey of nutrition knowledge and opinion of Wisconsin elementary teachers and food service managers. ERIC \# ED210108. 1981:1-91. Internet:

http://www.eric.ed.gov/ERICWebPortal/custom/portlets/recordDetails/detailmini.jsp?_nf $\mathrm{pb}=$ true\&_\&ERICExtSearch_SearchValue_0=ED210108\&ERICExtSearch_SearchType $0=$ no\&accno=ED210108. Accessed July 202009.

18. Hawkes AL, Nowak M. Nutrition knowledge questionnaire. Aust Fam Physician 1998;27(11): 1057-1058.

19. Holland MM. Childcare providers' perceptions of their influence on obesity in early childhood [dissertation]. Raleigh (NC): North Carolina State University; 2006.

20. Hughes S, Power T, Fisher J, Mueller S, Nicklas T. The development of the caregiver's feeding styles questionnaire. $J$ Am Diet Assoc. 2003;103(9):A-18.

21. Faul F, Erdfelder E, Lang AG, Buchner A. (2007). G*Power3: A flexible statistical power analysis program for the social, behavioral, and biomedical sciences. Behavior Research Methods. 2007;(39)175-191.

22. United States Census Bureau. Census Regions and Divisions of the United States. Available from http://www.census.gov/geo/www/us_regdiv.pdf. Accessed September 7, 2010.

23. International Nanny Association. 2009 International Nanny Association Salary and Benefits Survey. Available from http://internationalnannyassociation.blogspot.com/2009/05/2009-ina-salary-benefitssurvey-results.html. Accessed October 1,2010.

24. Gibbons K, Graham V, Marraffa C, Hendy L. 'Filling the gap' - children aged between two and four years: sources of nutrition information used by families and childcare staff. Aust J Nutr Diet. 2000;57:208-214.

25. Ollberding $N J$, Wolf RL, Contento I. Food label use and its relation to dietary intake among US adults. $J$ Am Diet Assoc. 2010;110(8):1233-1237.

26. Grifith S. Frequency of and factors associated with nutrition facts label use among adults [thesis]. Muncie (IN): Ball State University; 2009.

27. Evans A. Nutrition knowledge, attitudes, and practices among nutrition educators in the south. Am.I Health Stud. Available from http:/www.thefreelibrary.com/Nutrition knowledge, attitudes, and practices among nutrition...-a0152885708. Accessed November 202010.

28. Crogan NL, Shulz JA, Massey LK. Nutrition knowledge of nurses in long-term care facilities. J Contin Educ Nurs. 2001;32(4):171-176. 
29. Guthrie JF, Derby BM, Levy AS. What do people know and do not know about nutrition. Available from www.ers.usda.gov/publications/aib750/aib750m.pdf. Accessed October 1 2010.

30. USDA Agricultural Research Service Nutrient Data Laboratory. USDA national nutrient database for standard reference. Available at

http://www.nal.usda.gov/fnic/foodcomp/search/. Accessed on October 12010.

31. Hargrove IL. Does the history of food energy units suggest a solution to "calorie confusion?" Nutr J. 2007;6:44. Available at www.nutritionj.com/content/6/1/44. Accessed October 12010.

32. Wilcock A, Pun M, Khanona J, Aung M. Consumer attitudes, knowledge and behaviors: a review of food safety issues. Trends Food Sci Technol. 2004;15(2):56-66.

33. Nicklas TA, Baranowski T, Baranowski JC, Cullen K, Rittenberry L, Olvera N. Family and child-care provider influences on preschool children's fruit, juice, and vegetable consumption. Nutr Rev. 2001;59(7):224-35.

34. Baumrind D. Child care practices anteceding three patterns of preschool behavior. Genet Psychol Monogr. 1967;75(1):43-88.

35. Darling N, Steinberg L. Parenting style context: An integrative model. Psychol Bull. $1993 ; 113(3): 487-496$.

36. Patrick H, Nicklas TA, Hughes SO, Morales M. The benefits of authoritative feeding style: Caregiver feedings styles and children's food consumption patterns. Appetite. 2005;44:243-249.

37. Wright KB. Researching internet-based populations: advantages and disadvantages of online survey research, online questionnaire authoring software packages, and web survey services. J Comput Mediat Commun. 2005;10(3):article 11. Available at http://jcmc.indiana.edu/vol 10/issue3/wright.html. Accessed September 282010.

38. Position of the American dietetic association: Benchmarks for nutrition programs in child care setting. I Am Diet Assoc. 2005; 105:979-986. 
APPENDICES 
APPENDIX ONE 


\section{Knowledge, Behavior, and Beliefs of Nannies in Regards to Nutrition and}

\section{Intoduction and Consent}

Knowledge, Behavior, and Beliefs of Nannies in Regards to Nutrition and Children

Dear Association member,

I am currently a graduate student at Florida International University in the Department of Dietetics and Nutrition, who is working on a thesis project concerning Nannies. My interest in this area is based on the lack of nutrition research on inhome childcare. More specifically, the purpose of this study is to examine the nutrition knowledge and feeding behaviors of Nannies as well as to investigate whether Nannies believe they intluence the child's eating habits.

The research is supported by the International Nanny Association, the National Association for Nanny Care, and the Association of Premier Nanny Agencies, who have agreed to aid in the distribution of the survey, however are not in any way responsible for the content in the survey

You are asked to complete the following online survey and answer general questions about, 1) demographic information; 2) your nutrition knowledge, 3) your behaviors and feeding styles; and 4) your beliels on personal influence on children.

Complete only one (1) survey. Your consent to participate in this project is given upon completion of the survey Respond to the questions on the basis of what you presently know behave, and believe and please do not seek intormation from other individuals or outside sources including written literature and/or the Internet. All surveys are coded and you will not be identified The data will be reported as a group. No known rsks or benefits are aftorded to you by completing the survey. If you choose not to complete the survey no other action is needed.

If you have any questions about the study before or after you complete the survey, you may contact me at mgarz006@fiu.edu. You may also contact my major professor Evelyn B. Enrione, PhD, RD at enrionee@fiu edu or $305-$ 348 3236. If you have any questions regarding your rights as a volunteer in this research study you may contact $\mathrm{Dr}$. Patricia Price, the Chairperson of the FIU institutional Review Board at 305-348-2618 or 305-348-2494.

We appreciate your time and being a part of a process that will have an impact on childcare, nutrition education, research, and the body of literature in dietetics. Thank you for your participation.

\section{Sincerely,}

Melody Garza

Master's Graduate Student

Department of Dietetics and Nutrition

Florida International University

Miami, $\mathrm{FL}$ 


\section{Knowledge, Behavior, and Beliefs of Nannies in Regards to Nutrition and}

\section{2. ceneral In ormation and Denographes}

This section will gather background information about you. Please answer all of the questions

1. Which of the following associations do you or the agency you work for belong to? Check all that apply.

T. International Nanny Association

T National Association of Nanny Care

T Association of Premier Nanny Agencies

Tone of the above

2. What is your gender?

(T) Male

(1. Female

3. What is your ethnicity?

(. American Indian or Alaskan Native

C Asian or Pacitc Islander or Native Hawailan

C Black or Afrcan American

(. Hispancic or Latino

(0. White American or Caucasian

( Other (please specify)

4. What is your age?
(c. 18-24 years
25-34 years
(55-44 years
C. 45-54 years
C. $55-64$ years
C. 65 years and older 


\section{Knowledge, Behavior, and Beliefs of Nannies in Regards to Nutrition and}

5. What is the highest level of education you have received?
Hignschool
Q Yocatonalrechnica
Pिssoclate Degree
CBachelor's Degree
Masters oegree
Poctoral pegree
Other (please specin)

6. From what country did you receive your highest level of education?

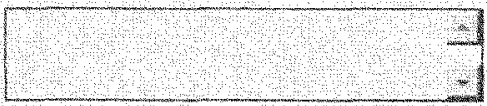

7. How many years have you been employed in the childcare profession?
7 Less than one year
$1-5$ years
16. 610 years
(1)20 vears
2130 years
31 years or more

8. What is your current employment status as a Nanny?

f Fullime ( 40 hours per week or more)

(Pantime (Less than 40 hours per week)

o Nol currently wonking as a nanny but looking for hire

C Not currently workng as a nanny and not looking for hire 
Knowledge, Behavior, and Beliefs of Nannies in Regards to Nutrition and

9. What is your current employment status as a Nanny?

Liverin

$\Gamma$ Non ive in

( Both (explain!

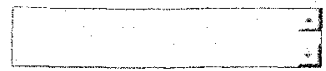

10. How many families currently employ you as a Nanny?

r 1

$r z$

53

C 4 or more

11. Are you related to one or more of the families who employs you as a Nanny?

r. Ves

C No

li yes, what is the relation?

12. What state do you currently live in?

13. What state(s) do you work in as a Nanny?

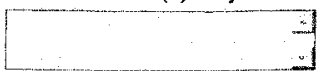

14. How many children do you currently care for as part of your employment as a Nanny?
$r 1$
$r_{2}$
$r_{3}$
$r_{4}$
C. 5
r. 6 ormore 
Knowledge, Behavior, and Beliefs of Nannies in Regards to Nutrition and

15. What is the age of the children you currently care for as part of your employment as a Nanny? Check all that apply.
Thlans (Bith 12 months)
Toddlers (1 2 years old $)$
Preschool $(0-4$ years old $)$
TS Schoolage $(57$ year old $)$
T. Adolescents (B.14 years old)
T5 years and older

16. What is the average yearly income of the family (or families) that employ you as a Nanny?
r Less than $\$ 100,000$
O More nan $\$ 100$ ooo
C Not Sure
Bothlexplan)

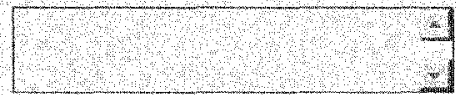

17. Are you employed by a single- or dual-parent household?
C. Single Parent Housenold
C Duar parent Household
Coth fexplain

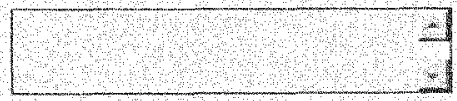

18. Do you have any children of your own?
ryes
rNo

If yes now old are your children? 


\section{Knowledge, Behavior, and Bellets of Nannies in Regards to Nutrition and}

19. When was the last nutrition workshop, class, lecture, and/or information session you attended?
r 16 months ago
C.12 months ago
613-24 months ago
C 2536 months ago
C 5 years or more ago
S Never attended

20. From what source(s) do you receive your nutrition information? Check all that apply.

THealth Care Prolessionals

T Print Media (Newspapers, Books, Magazines, Newsleters, Eyers)

T Non Pint Media (felevision fado, Intemes)

P Relatives

PFiends

Tr. Foodlabels

Tentrition/Supplement stores

T Other (please specify) 


\section{Knowledge, Behavior, and Beliefs of Nannies in Regards to Nutrition and}

3. Nhmon haruege

This section will gather intormation pertaining to your knowledge with regard to nutrition Please consider each question before responding and choose the best answer

1. Classify the following as either a FOOD or NUTRIENT.

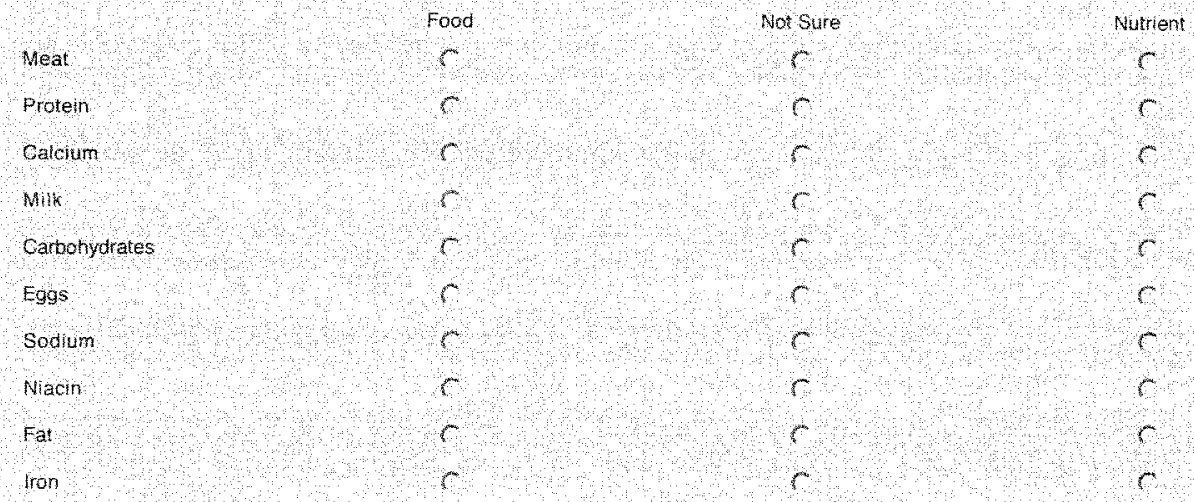

2. Cholesterol is found only in animal products:
1) True
CFatse
C Nor Sure

3. The main ingredient in a food is listed FIRST on a food label:
C. True
rfalse
C. Not sure

\section{A kilocalorie (calorie) is a measure of:}
The amoun of heat required to digest the food we eat
The energy value ar food
C. Fat vitamin, carbohydrate content ol tood
C. Carbohydrate, protein tat content of tood 
Knowledge, Behavior, and Beliefs of Nannies in Regards to Nutrition and

5. Which of the following are paired correctly?

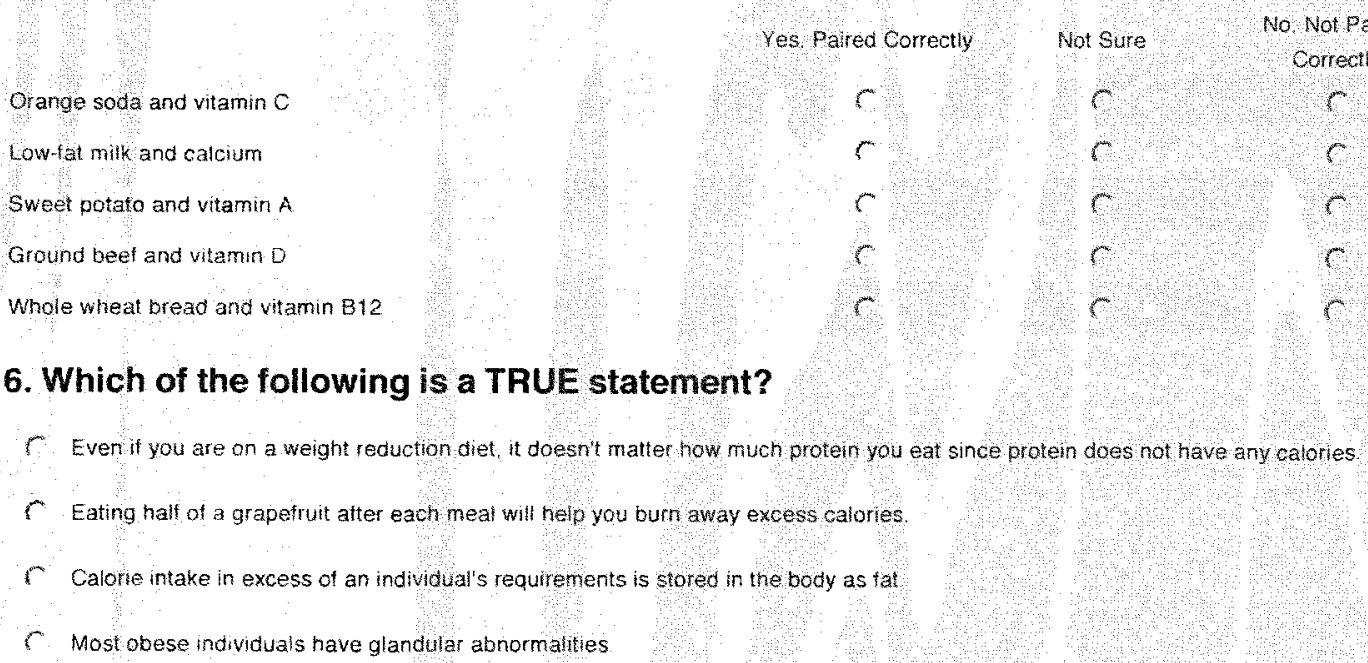

7. Which of the following meals best represents the dietary guidelines of the United States' Food Guide Pyramid?

Chicken, broceoll fice, milk, fruit saiad

Spaghetti, Alffedo sauce bread, butter iced tea

r. Hamburger, bun, fries coke

Spinach salad with fomatoes and carrots; oll and winegar garlic toast milk

\section{Which of the following makes food safe?}

Hand washing

Using the same cutting board for raw poutry and vegetables

Thawing trozen chicken in the sink

Freezing loods to kill bacteria

Keeping the refrigerator between 45 and 65 degrees Fahenhent

\section{Which has less fat?}
Butter
Cregerable ol
Tothay are equal
not sure 
Knowledge, Behavior, and Beliefs of Nannies in Regards to Nutrition and

10. Which of these foods have fiber?

Steak

Baked beans

Apple lute

Whole Wheal 8 read

ssh

Oranges

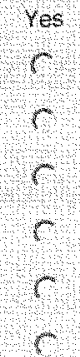

Not Sure

(a)

+o

1

$\beta^{m}$

(r)

3
No

rn

r

$\mathrm{s}$

s

,

69 


\section{Knowledge, Behavior, and Beliefs of Nannies in Regards to Nutrition and}

\section{Nutriton behaviors - reeding styles}

These section displays questions that deal with YOUA interactions with the children you care for during a meal choose the best answer that describes how otten these things happen, if you are not certain, make your best guess

\section{How often during the meal do YOU say the following or something similar?}

1 "If you hinst you vegetables, you wil gof some ce crean"

2. "lyou eat your beans, we can olay atter dinner"

3. What a good boy! You'te eating your vegetables"

4. "Eat your dinner, is getting cold"

5. "Hurry up and eat your tood."

6 "Milk is good for your health because it will make you strong."

7. "If you don't finish your meal there will be no play time atter dinner."

B. "You need to eat your fruit."

9. "ff you dont finish your vegetables, you won't get candy"

\section{How often during the meals do YOU...}

10. Arrange the food to make interesting (for example, making smiley laces on the pancakes)

11 . Ask the chtdquestions about the tood

12 rell the chid to eat at least a littre bi of tood on his or her plate.

13. Say somethng to show your disaporoval of the child for not ealing the meal.

14. Allow the chid to choose the foods he or she wants to eat for the meal from $\$ o o d s$ aleady prepared

15. Say something positive about the tood the child s eating during the meal

16 spoon-fed the chud to get him of her to eat he neal

1 Help the child to eat dine, for example, cutting the food into smaller poces

18. Restran a chid reluctant to ea

19 Begthe chid to eat dime

\begin{tabular}{|c|c|c|c|c|}
\hline Never & Farely & Sonetimes & $\begin{array}{l}\text { Most of the } \\
\text { Time }\end{array}$ & Always \\
\hline$r$ & & s & $r$ & $r$ \\
\hline r & r & $r$ & $x^{m}$ & $r$ \\
\hline$i^{n}$ & sin & $r$ & $r$ & क \\
\hline$?$ & $r$ & r & $r$ & 8 \\
\hline 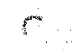 & $r$ & 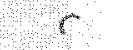 & $x^{2}$ & \% \\
\hline$r$ & 6 & 8 & 6 & 6 \\
\hline$c$ & $r^{m}$ & $\infty$ & 8 & ro \\
\hline 6 & $r$ & r. & ra & 8 \\
\hline 6 & $r$ & $4{ }^{\mathrm{e}}$ & 1 & 1 \\
\hline
\end{tabular}

Aam sometnes The Aways

\begin{tabular}{|c|c|c|}
\hline$r$ & $r$ & \\
\hline$r$ & $r$ & \\
\hline$R$ & $r$ & \\
\hline$C$ & $r^{2 *}$ & \\
\hline$f_{:}^{m i n}$ & $F$ & \\
\hline 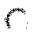 & s & \\
\hline$t^{m}$ & 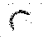 & \\
\hline $\mathrm{C}$ & $c^{*}$ & \\
\hline$t^{m+4}$ & $r$ & \\
\hline 5 & S & \\
\hline
\end{tabular}


Knowledge, Behavior, and Beliefs of Nannies in Regards to Nutrition and

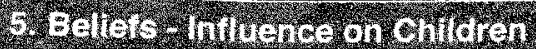

This section will gather information pertaining to your personal and professional beliefs with regard to the intuential role you may have on the children under your care. Please consider each question before responding and choose the best answer.

1. Who shops for the food and/or snacks that the children you care for eat?

$$
\begin{aligned}
& \text { C You } \\
& \text { The parents } \\
& \text { Both } \\
& \text { Other (olease specify) }
\end{aligned}
$$

2. Who decides what food and/or snack choices the children have to eat? Check all that apply.

$$
\begin{aligned}
& \text { Parents } \\
& \Gamma \text { Myself } \\
& \text { T Other (please specity) }
\end{aligned}
$$

3. Do the parents consider/value your opinion when it comes to what foods and/or snacks to give the children?

$$
\begin{aligned}
& C \text { No } \\
& C
\end{aligned}
$$

4. Do you give the child (children) snacks?

$$
6 \text { Yes }
$$

If no. explain (why and who gives the snacks!

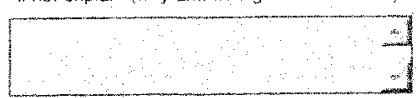


Knowledge, Behavior, and Beliefs of Nannies in Regards to Nutrition and

5. How often is (are) the child (children) given snacks?
Onceaday
Twice a day
Three or moretimes a day
Snacks are not given
Other (explain)

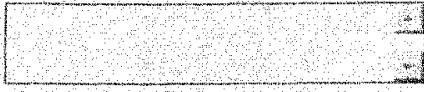

\section{How often do the following occur?}

leat the same foods werked to the onldren

Itring food from home

J order hom a restauran tor pick up or delivety to teed my sel

i skip most meals while carno tor the childen

leat with the children

clear while the chidren eat

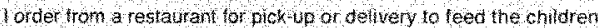

$$
\begin{aligned}
& \text { Ne } \\
& \text { Neye }
\end{aligned}
$$$$
\text { Rarel }
$$$$
\text { Sonetmes }
$$$$
\text { Nost of the }
$$$$
\text { Time }
$$

Always

का 3

$r \quad 3$

r 2

$\mathrm{C}$

m 2

r d

क 4

pis

$r$
$r$
$r$
$r$
$r$
$r$
$r$

r.

e

r

e

$\mathrm{s}$

r

$r$

r

s

r

$r$

7. The person(s) who has/have the greatest influence on eating habits of the children you care for is/are:
Parentsquardians
Siblings
Myself
Peers
G Grandparerts
Other please specify? 


\section{Knowledge, Behavior, and Beliefs of Nannies in Regards to Nutrition and}

8. Do any of the children you care for as a Nanny require special dietary needs?

$$
\begin{gathered}
\text { res } \\
\text { No }
\end{gathered}
$$

If yes phease specify.

\section{As a Nanny, the importance you place on:}

Veu Important

Somewhat

Neitral

Somewhat

Very

Unimportant

Inimoontant

Assistng the onldren in maint aming a healhy weight

$$
\text { on }
$$

Assisting the chidren who are overweight hlosing weight

Serving the ohitdren meals and snacks that you would consider nutritious

Chidren receiving approphate nutrition education duno early childhood years

$\sqrt{4+4}$

r

C.

(3) r

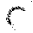

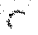

r s.

$a^{3}$

$r$

$r^{+\infty}$

10. As a Nanny, you would describe your influence on:

Veryngh

bofluence

The nutritional habits of the chidren in your cares The nutrition education that the chileren in your cate receive as

\section{Somewhat}

High

mfluence

$c$

C

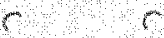

Noderate

Inthence

Sornewhat

Low Influence

Verlow

mituence

Wo ntuenes
C

r

r

स

a
$\mathrm{w}$

a.

$r$

r

a 


\section{Knowledge, Behavior, and Beliefs of Nannies in Regards to Nutrition and}

\section{6. $10101 \%$}

This is the end of the survey. Thank you for your time and cooperation in completing this survey

For questions, comments, or concerns please feel tree to contact me or my major protessor at:

Melody Garza

mgarz006@fiu.edu

Evelyn B. Enrione, PhD, $\mathrm{AD}$

entionee@fiu,edu

$305-348-3236$ 
APPENDIX TWO 


\section{AP PERDIX 8}

Wiscons in WE Wutrition knowledge Test - Leval, 2, Fan 8

testructions:

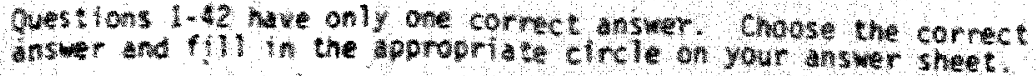

in

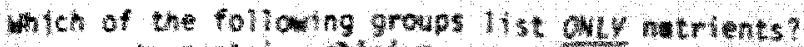

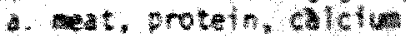

b. Wilk, chese, sogs

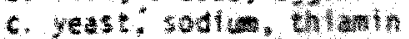

d. proter, fat, irot

2

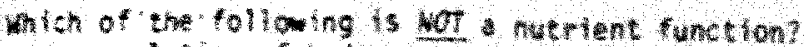
a. regulation oody protess
b. soply of encry
c. lubrication of sody joints

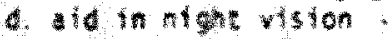

3

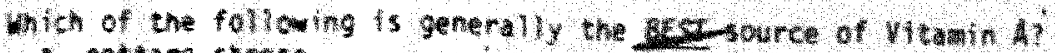
a. cotrage chess
1. Truks and ratables
C. 3 ars
4. pontery and 1su

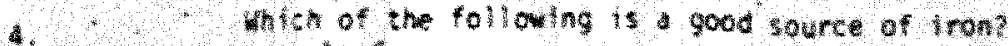
3. bet

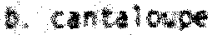
6.
4. pocom

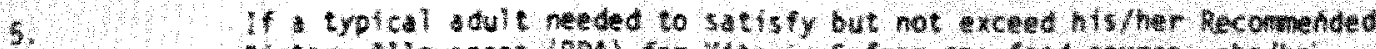

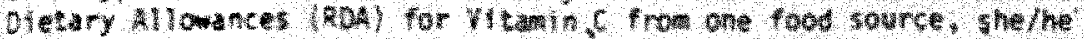

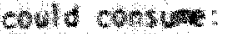

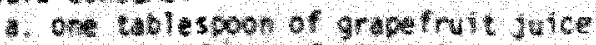

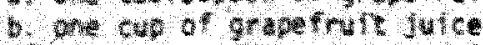

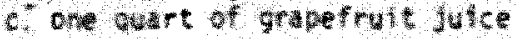

(6.

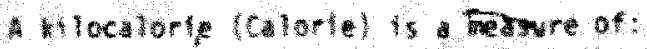

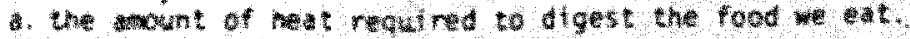

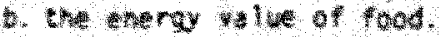

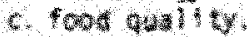

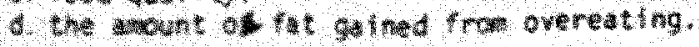

.

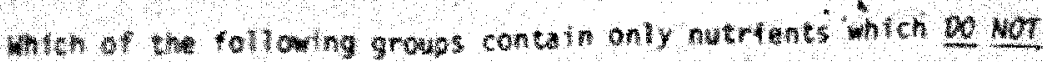

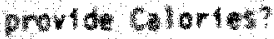

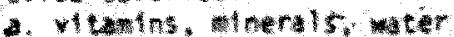

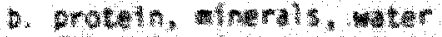

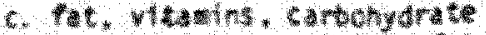

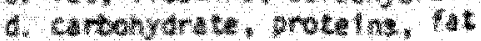
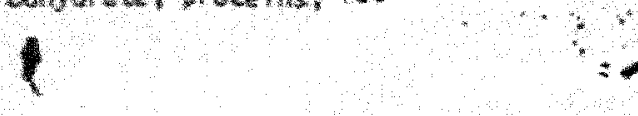

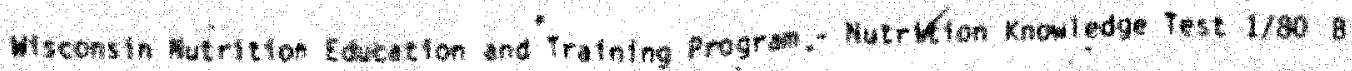




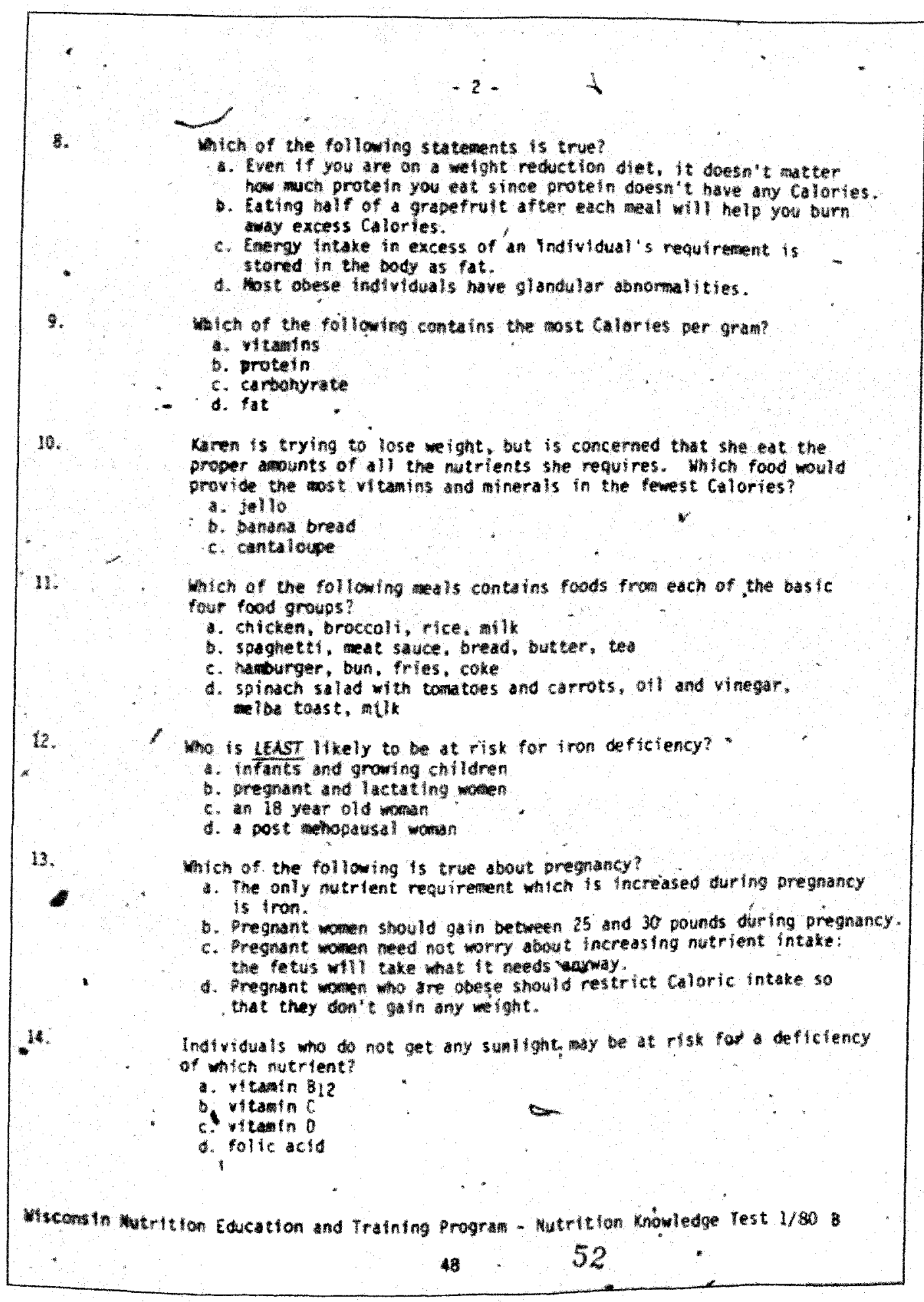




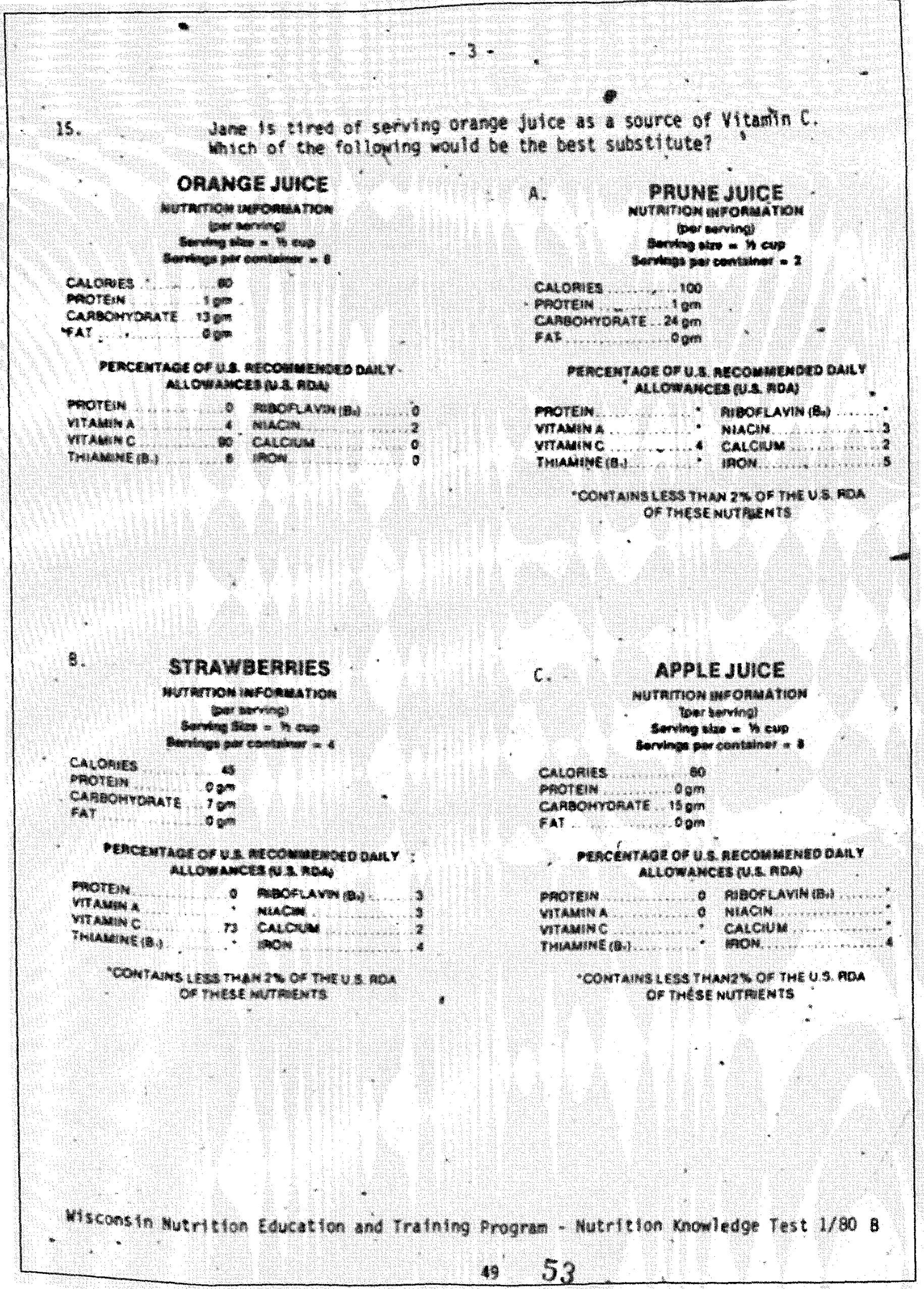




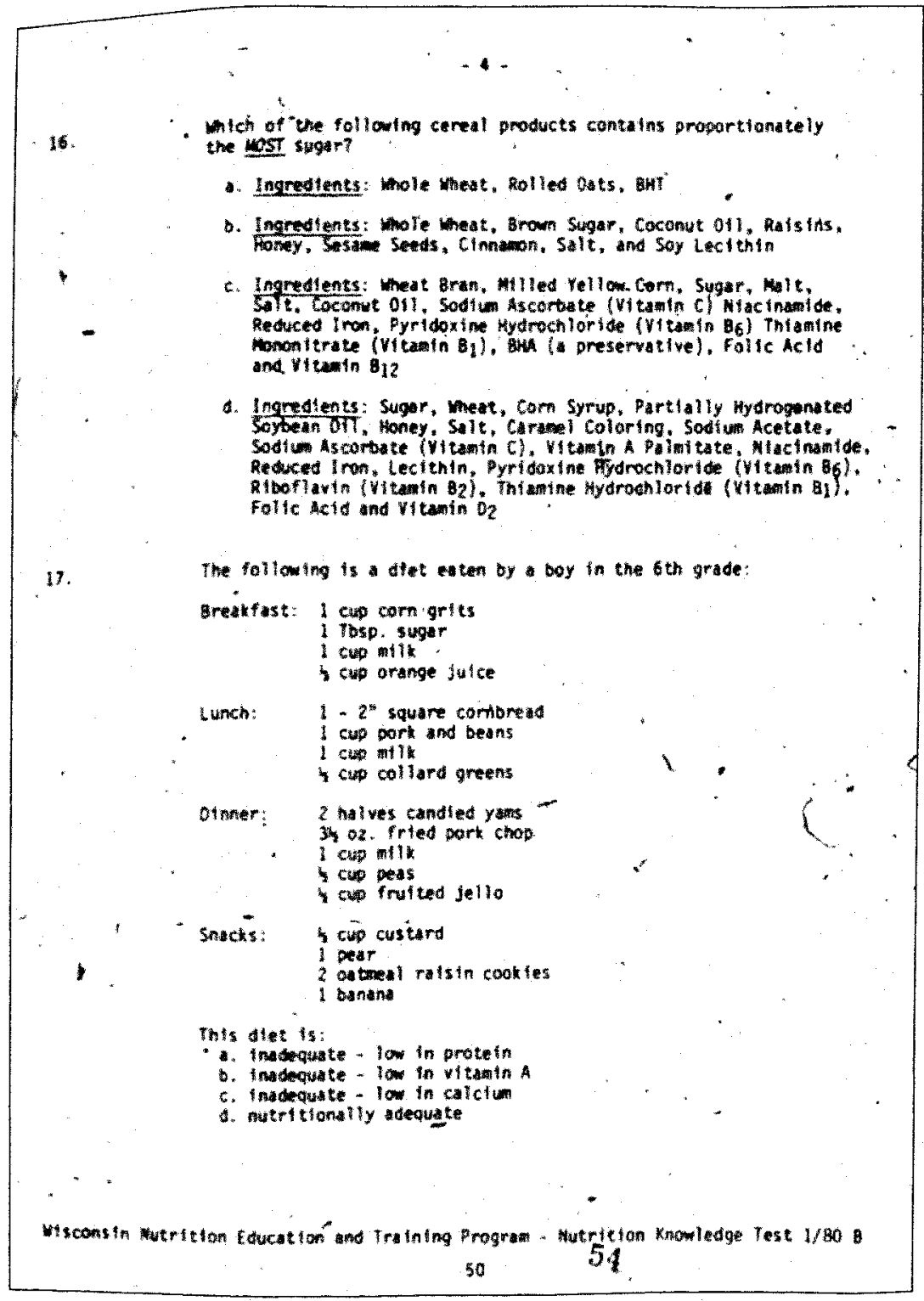




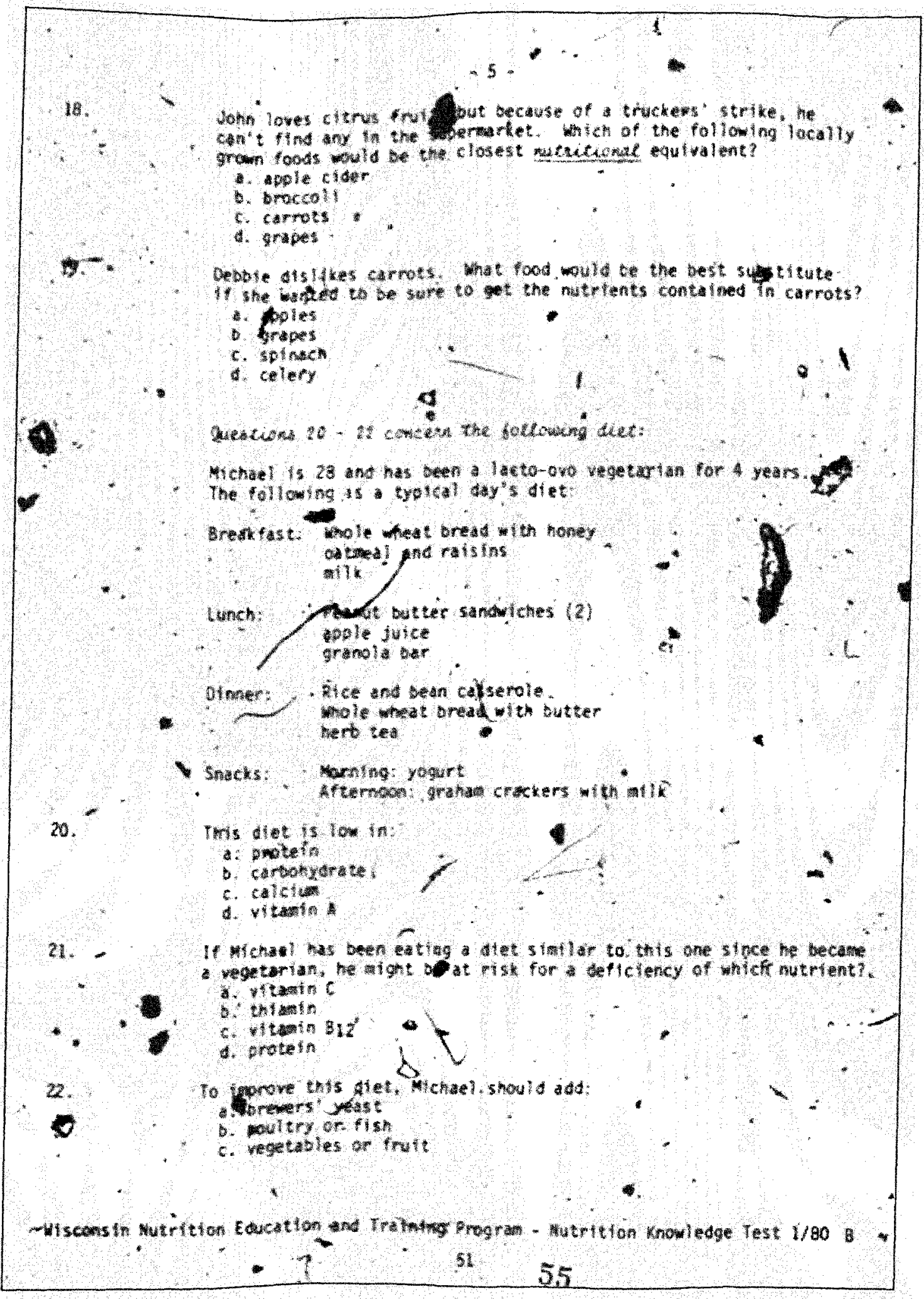




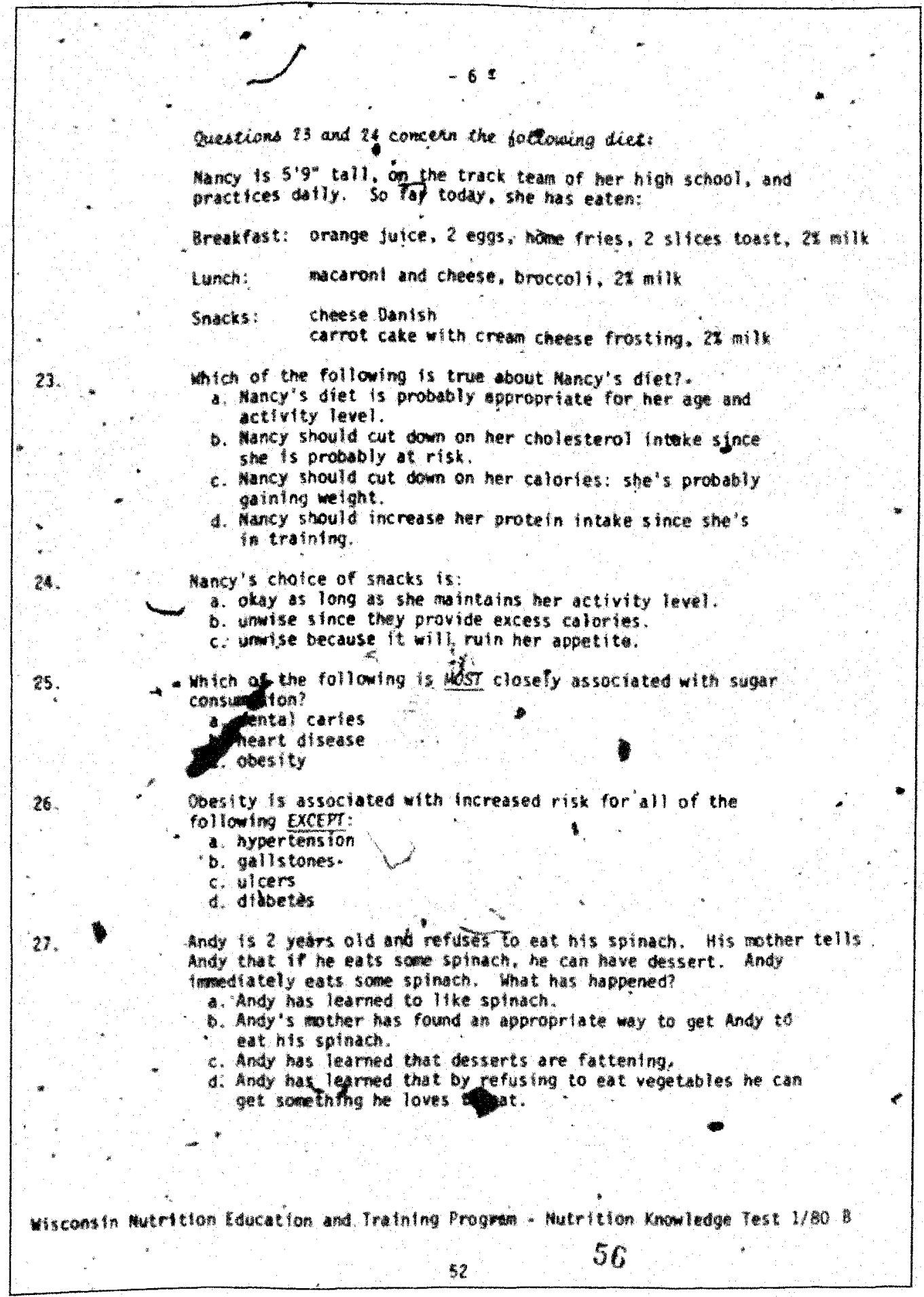




$$
+7 .
$$

28.

An example of the way in wich me-mory qualy of tood ray affect its consump tion : 15 :

a. BII eat wole graths because they ane nutritious.

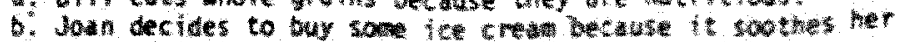
sore throet:

c. Lyan euts raisins becuse they are his in irot.

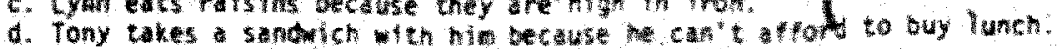

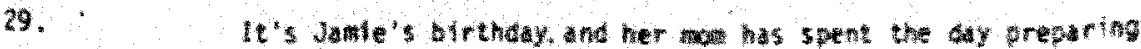

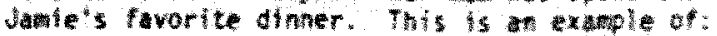

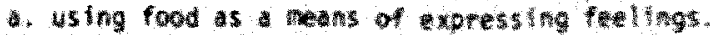

b. the effect of culture on food chorce.

c. using food as autrient soure.

30.

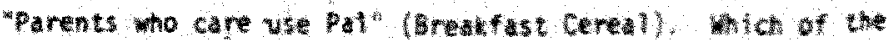
tollowing is bethg used to selly gal?

d. The nutritional content of Fi coecente to othe brands.

b. The psychological destre to be good parent.

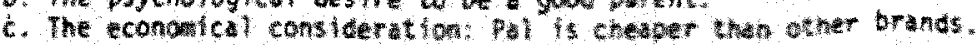

a. The toste foctor: Pal tastes betzer than other brands.

31.

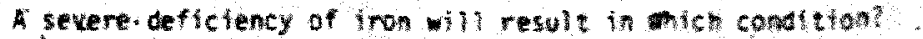
a. anevida
- b. beri bert
c. pellagra
d. seurvy

32.

- Which of the following is the Best example of protein conplenentation?

a. exting bor and eggs

b. eating beass and rice

c. eating peas and carrots

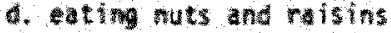

33.

10 taprove the prote in qually of bred. it could be eaten with:
* butter
b. getatin
*c. peanut butter

34.

Which of the following sources of protein requires the LEST food resources to produce?

a. Dans.

b. beet

c. egas

d. povitry

35.

Not long ago, fresh oringes ant grapefrut we deltestses in

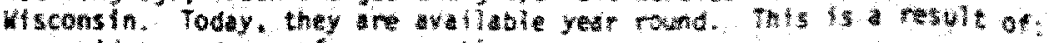

- widespread use of preservatives.

8. Increased metability in the north.

c. Improved transportution sys fears.

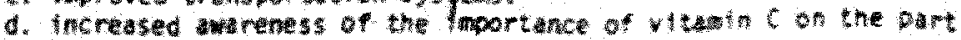
of Northerners:

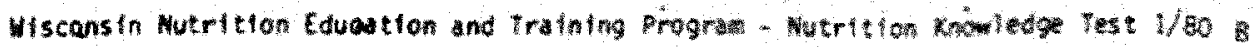




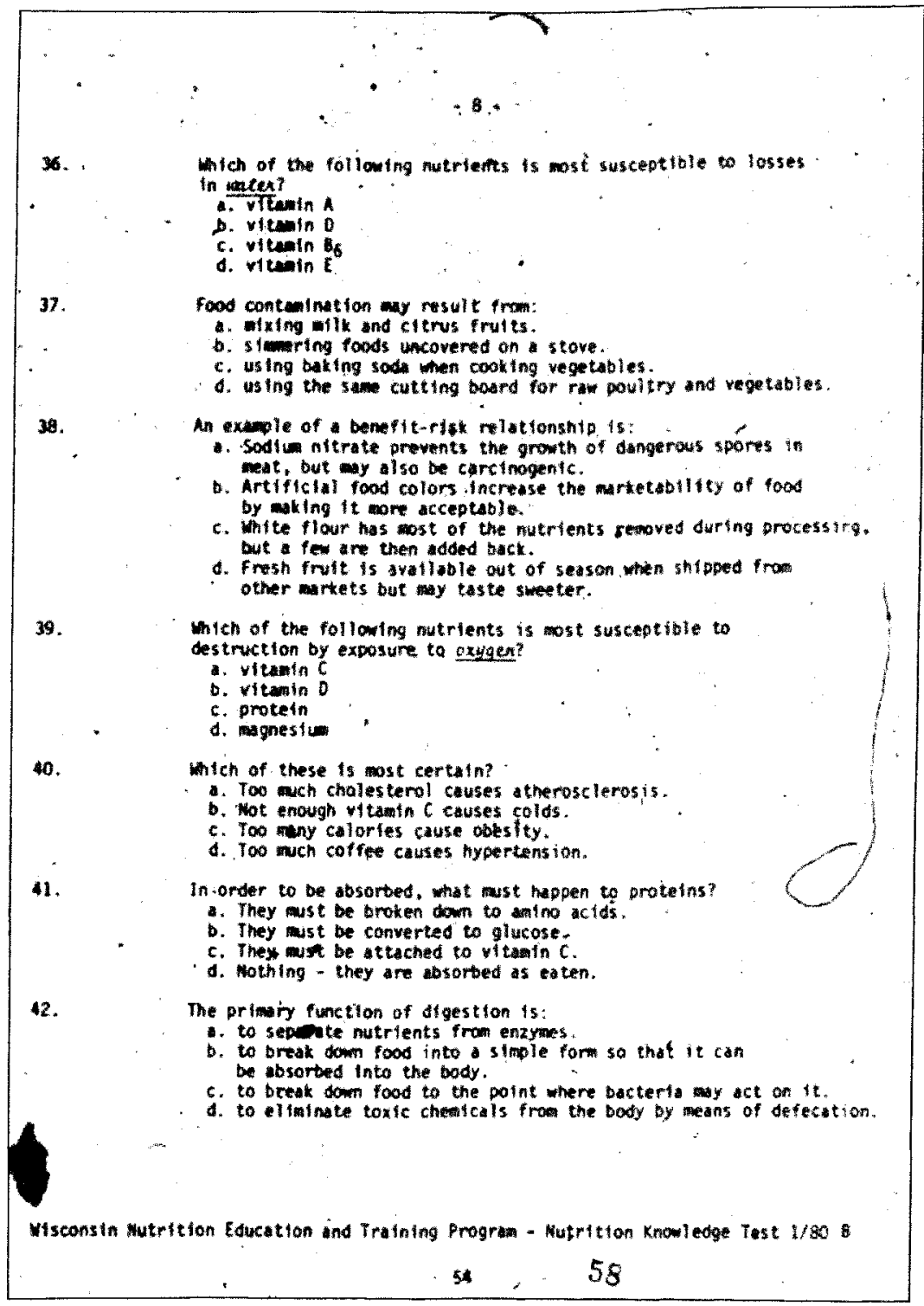


APPENDIX THREE 


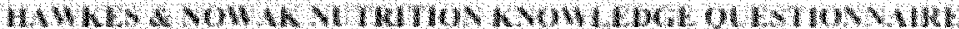

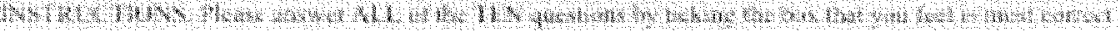

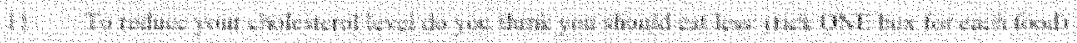

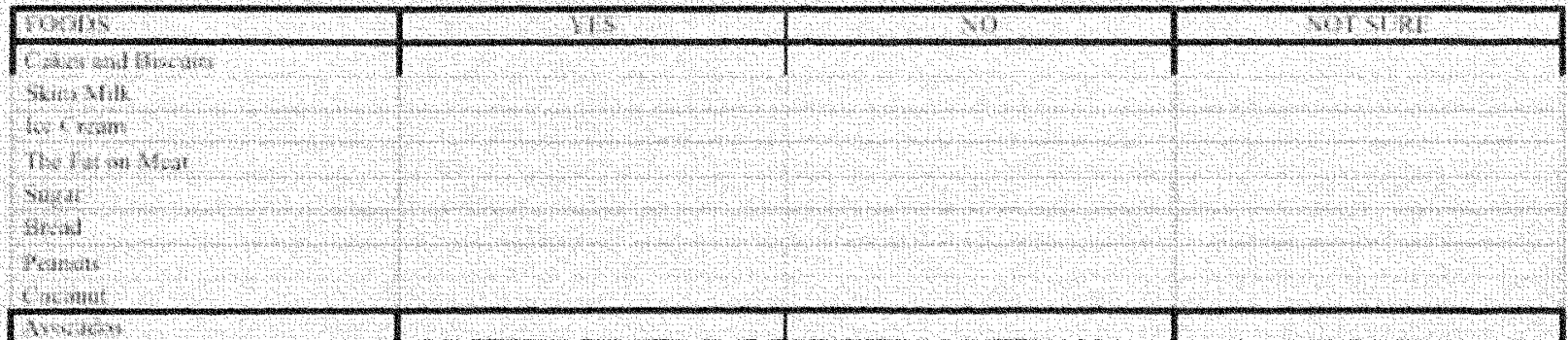

T:

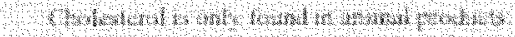

$$
\text { Whe }
$$

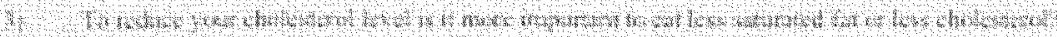

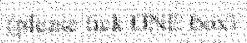

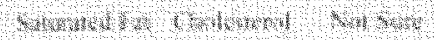

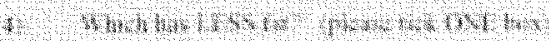

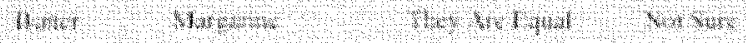

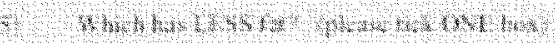

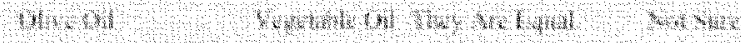

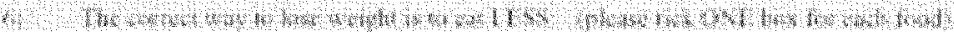

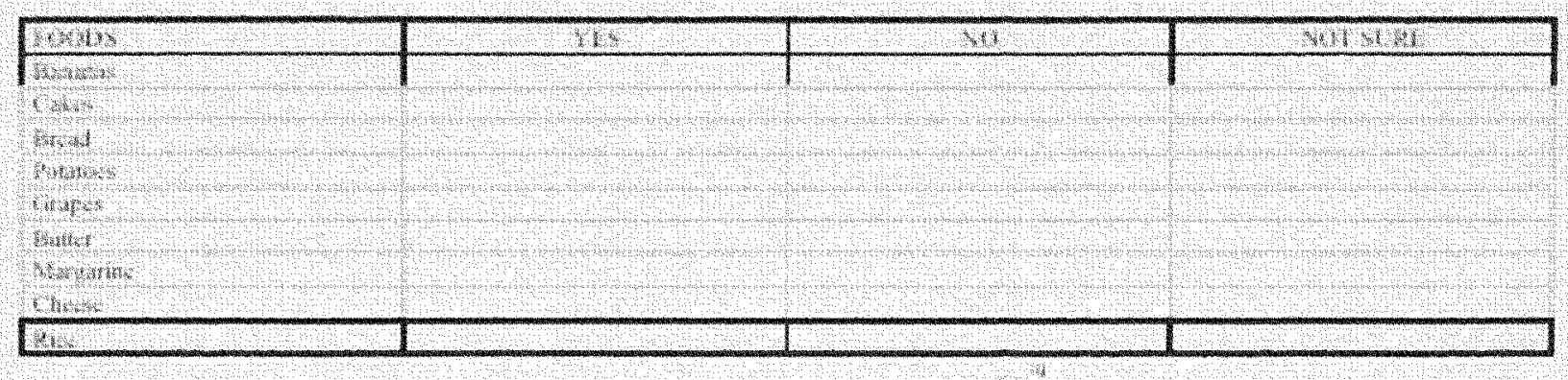

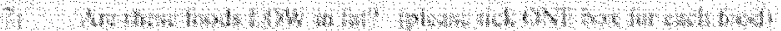

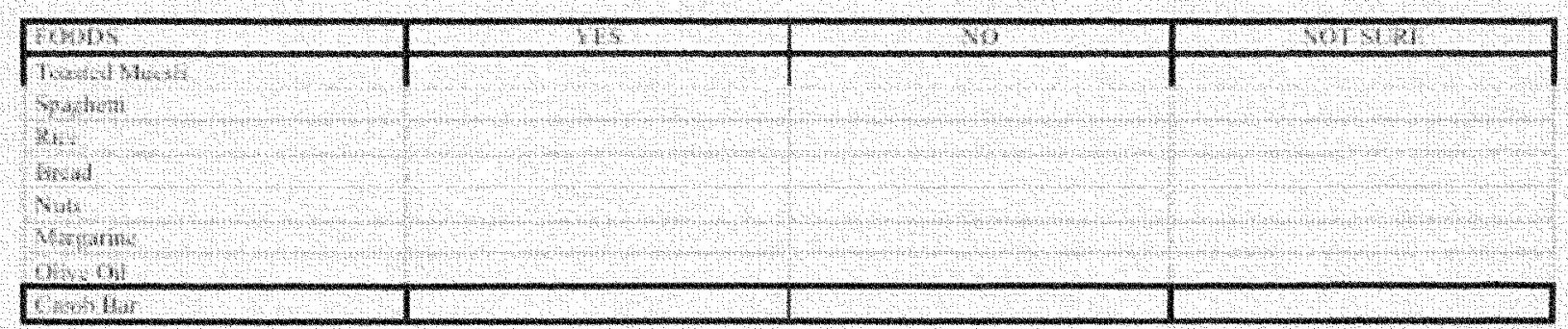

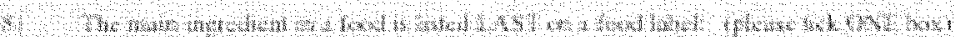

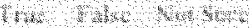




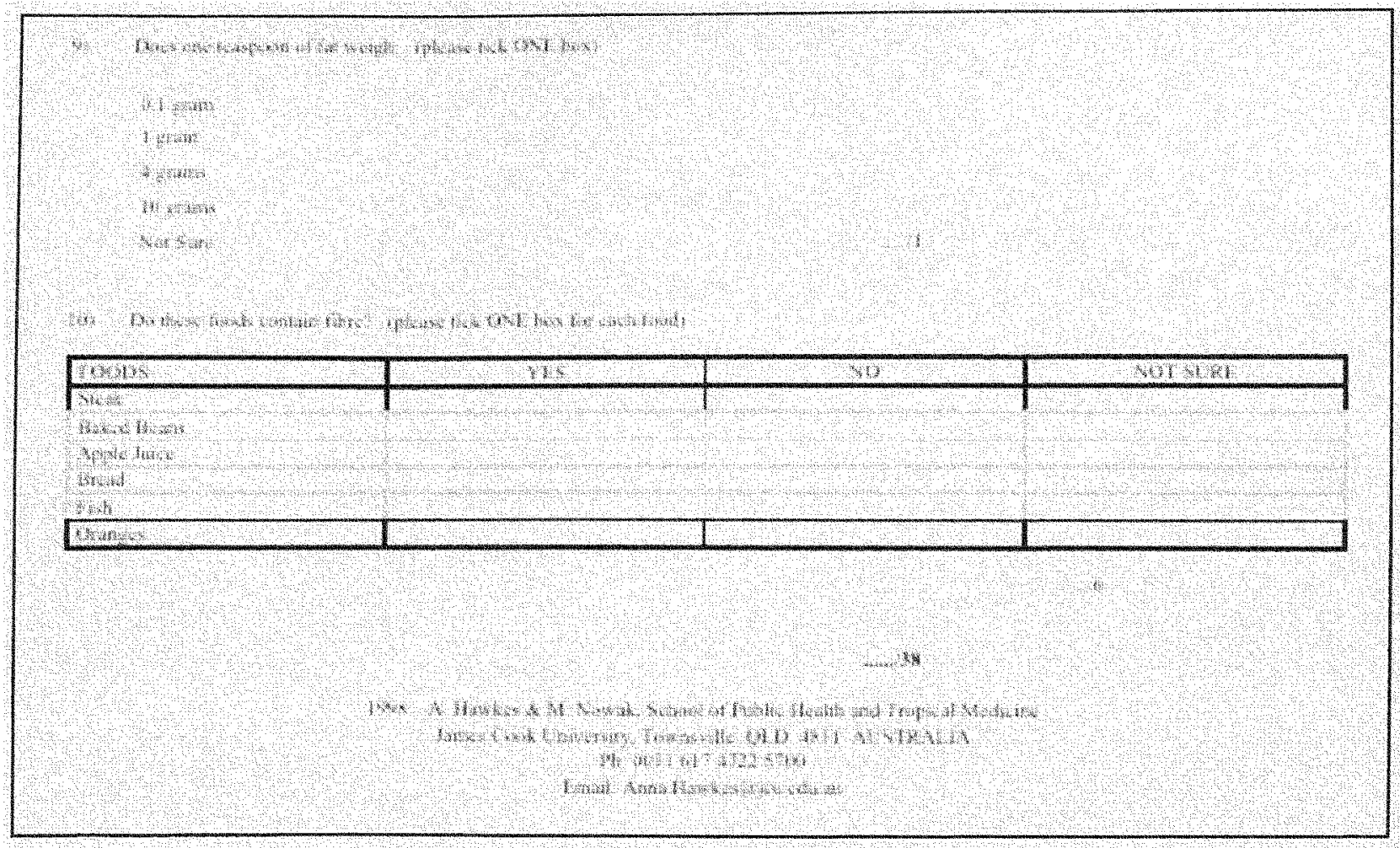


APPENDIX FOUR 
1. My current employment status in childcare is:

A. I am currently employed in a childeare facility.

B. I am not currently employed in a childcare facility.

2. I have been employed in the childcare profession for:
A. Iess than I year
B. 1 year 105 years
C. 6 years to 10 years
D. 11 years $t \mathrm{~s} 20$ years
E. 21 years to 30 years
F. 31 years or more

3. My current position is:
A. Teacher Assistant
B. Classroom Teacher
C. Lead Teacher
D. Director or Assistant Director
E. Other:

4. The type of childeare factity where I am employed is:
A. for-profit center
B. government-operated or non-profit center
C. religious-atriliated center
D. family child care home

5. The "stur-rating" of the childeare facility where I am employed is:
A. 5-star
B. 4-star
C. 3-star
D. 2 -itiar
E. I-star
F. I don't know/facility is not licensed under the star-rated system 
6. The number of employecs at the chilucane facility where I work is:
A. $1-4$ employeces
B. $5-10$ employees
C. 11-15 employees
D. $16-20$ employees
E. 21 or more employees

7. The age of clild I am primarily assigned to teach is.
A. infants
B. toddlers
C. 2-year-olds
D. 3 -ycar-olds
I. 4 \& 5 year oids
F. *howl-age children

8. The number of children in my class is:
A. 1.5
B. $6 \cdot 10$
C. 11.15
D. $16-20$
E. $21-25$

9. Think of an individual who has a powor sell-concept. That person would be on step I of the scale to the raght. A person with a great self-concept would be on step 10 of the scale on the right. With "I" being a poor selt-concept. and "10" beang a great self-concept, please rate yourself on the scale:
A. Step I
B. Stcp 2
C. Step 3
D. Step 4
E. Step 5
F. Stcp 6
G. Step 7
11. Step 8
1. Step 9
1. Step 10

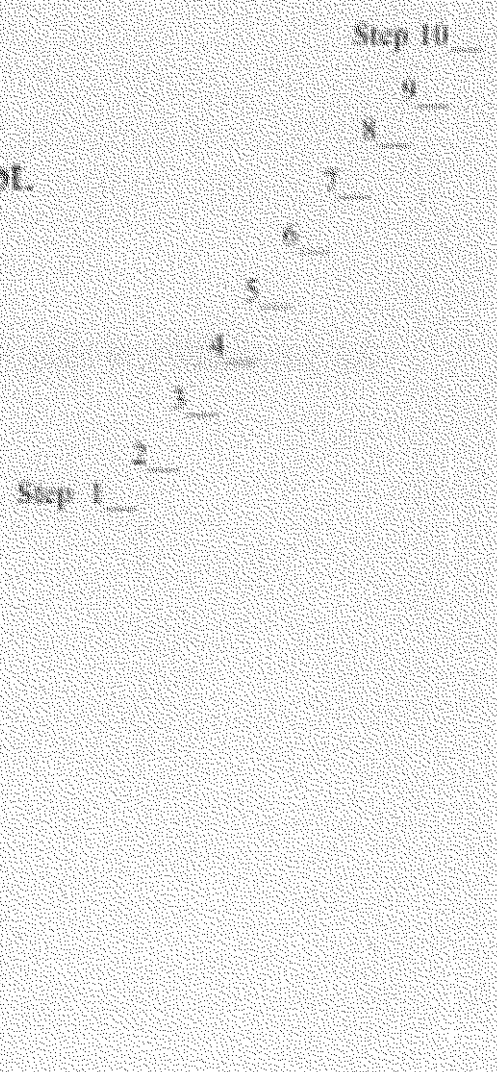


10. Think of an mdi lual with a pow gualigy of the Nhal person cruld be on step $/$ of the scald 10 lic right. A person with a greal quality of

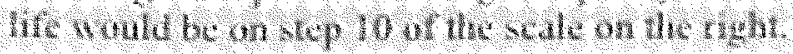

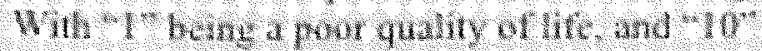
being a greal quality of life, fate yout personal qualley of whe wr the scale de the with
A. Stepl
B. Sing 2
C. Step?
D. Step 4
1. Steps
1. $\operatorname{sing} 6$
6. Shes?
11. 516 in
I. $\operatorname{sen} 9$
I. $51+110$

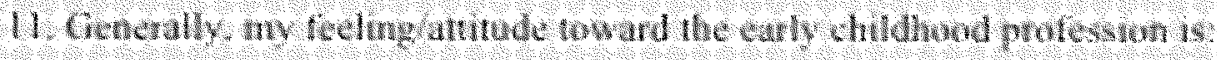
1. Vers posine
1. Swheshor posine
C. Neutral
1. Swnewher negurve
E. Verv nergative:

12. Gencrally, oy fedmg arutude loward wy present wo in chideare is
A. Very postive
8. Sonrewhat positwe
c. Neutral
D. Somewhat megatwo
E. Vory negante

13. 1 would describe ay own wergh is
A. very under weathe for my herght and frums:
D. sightly undinvight for wy hemble and trime
C. rumal werght for m keight ard trunc:
D. shumy overwemht for my hewhe and hum.
1. sery overwerght for my lerght and fram 
1. I thethe

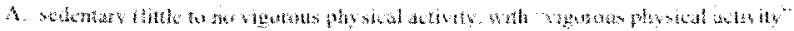

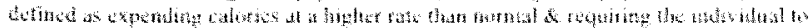

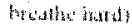

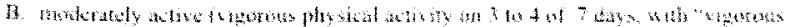

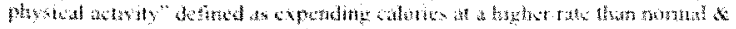

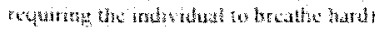

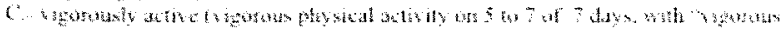

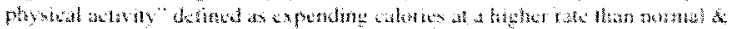

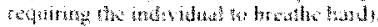

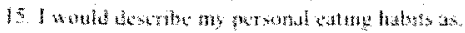

1. I edt

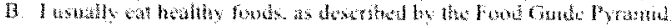

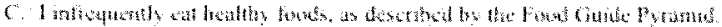

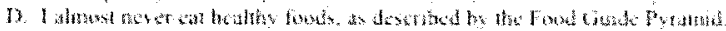

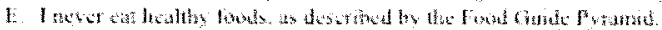

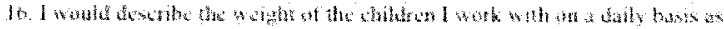

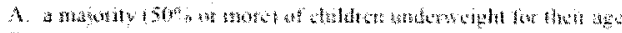

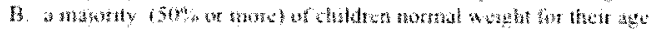

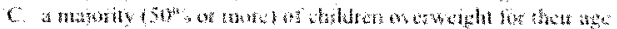

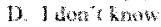

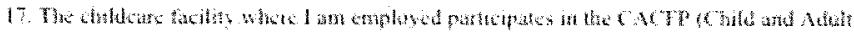

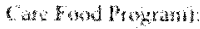
A. Is
13. Vis

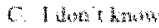

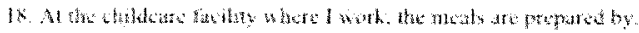

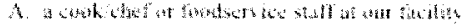

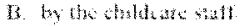
C. is

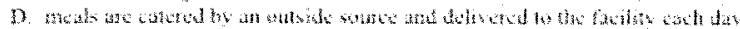

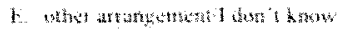


19. Please rank the following factors that influence menus at the childeare facility where you work, with " 1 " being the greatest influcntial factor and "6" being the least inhuential factor.

A. cost of rood

B. nutritional quality of food

C. children's preferences acceptance of food

D. regulations

E. case of preparation

F. other:

20. For $50 \%$ or more of the meals that I eat while working at clitidcare, I:
A. eat the same foods served to the children
B. bring a bag sack lunch from home
C. order out from a restaurant for pick-up or delivery
D. skip most meals at work
E. none of the aboverother

21. While the children are eating meals, $50 \%$ or more of the time I am.
A. cating "family-style" with the children
B. cleaning or straightening the room
C. serving/supervising the children and circulating around the dining tables
D. other

22. On three of every five days at the childcare faclity where I work, I feel that the snacks that are served to the children are:
A. very healthy, according to the Food Guide Pyramid
B. somewhat healthy, according to the Food Guide Pyramid
C. somewhat unhealthy, according to the Food Guide Pyramid
D. very unhealthy, according to the Food Guide Pyramid

23. The last training workshop on nutrition that 1 attended for my job was:
A. $0-6$ monthis
B. 7.12 months
C. 13-24 months
D. $25-36$ months
E. more than 5 years ago 


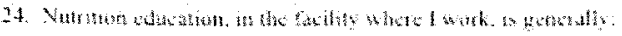

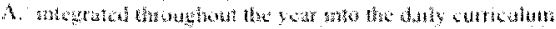

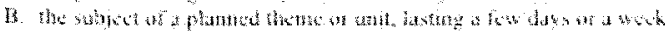

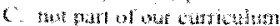
1).

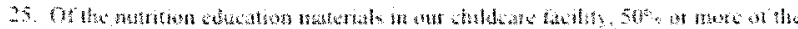

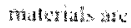

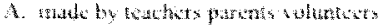

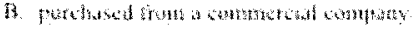

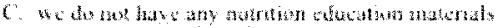

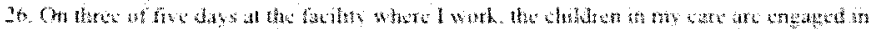

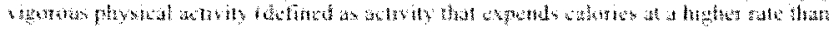

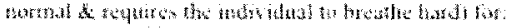

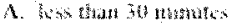
18. 30 ramutes to ! hous

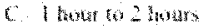

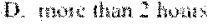

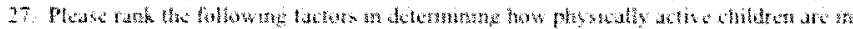

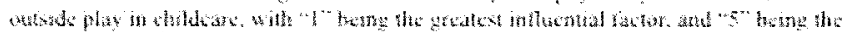

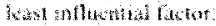

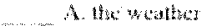

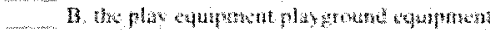

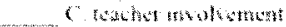

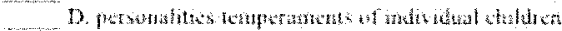
I. athe facturs

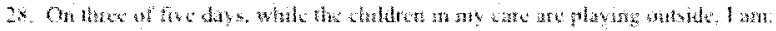

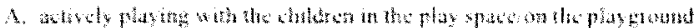

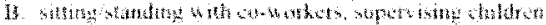

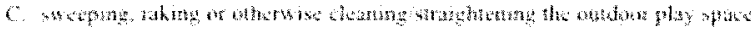

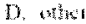




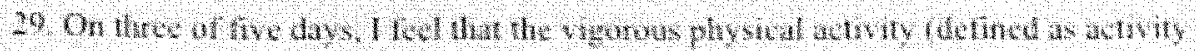

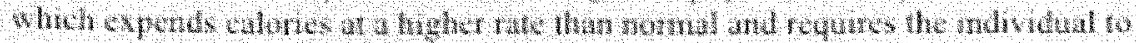

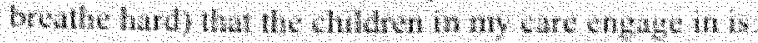

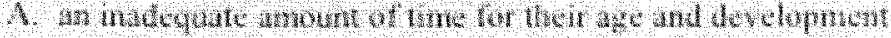

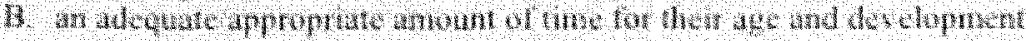

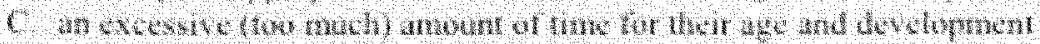

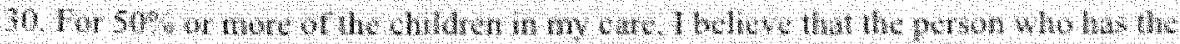

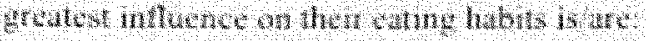

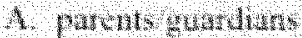
B. siblings:

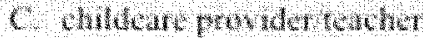
D restes

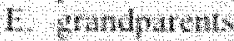
1. olluch

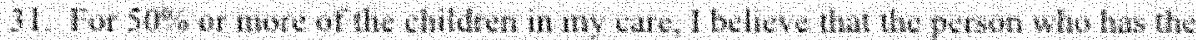

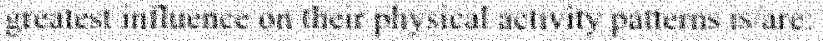

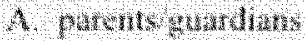
13. Whos
C whlacare prowder wawher
D pors

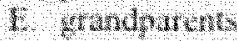
1. other

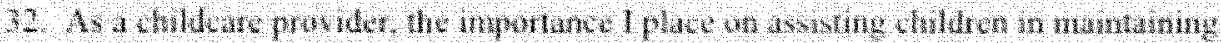

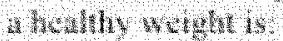
A I is woty mifotarn whe

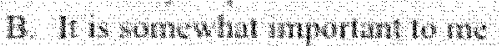

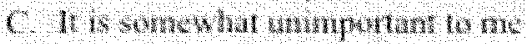

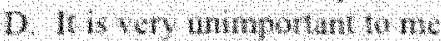

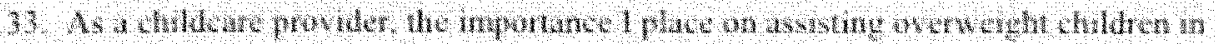

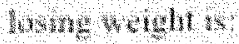

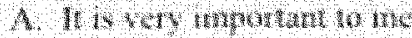

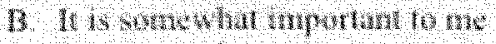

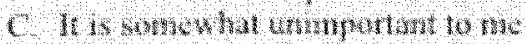

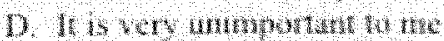


34. As a childcare provider, the importance I place on serving children meals and snacks that I would consider to be nutritious is:
A. It is very important to me
B. It is somewhat important to me
C. It is somewhat unimportant to me
D. It is very umimportant to me

35. As a chuldeare provider, the imponance I place on children receiving what I consider to be sufficient physical activity each day is:
A. It is very important to me
B. It is somewhat important to me
C. It is somewhat umimportant to me
D. It is very unimportant to the

36. As a childcare provider, the importanee I place on children receiving appropriate nutrition education in their early childhood curriculum is:
A. It is very important to me
B. It is somewhat important to me
C. It is somewhat unimportant to me
D. It is very unimportant to me

37. I would describe my influence as a childeare provider on the nutritional habits of the children in my care as:
A. Very high influence
B. Somewhat high influence
C. Moderate influence
D. Somewhat low influence
E. Very low influence
F. No intluence

38. I would describe my influence as a childeare provider on the physical activity habits of the children in my care as:
A. Very high influence
B. Somewhat high intluence
C. Moderate influence
D. Sonewhat low influence
E. Very low influence
F. No influence 
39. I would describe my influence as a chiddcare provider on the nutrition edacamion that the chidaren in my cure receive as.
A. Very lugh intweres:
B. Somerwhat high inlluence
C. Mudiurate untuenue
D. Somewhin low maluence
I. Very low Intherce
F. No intluerice

40. I would describe my inhuence on a child's diet and phy weal actrvity when the child as at bome and not in any care as.
A. Very hoh inhuence
B. Somewhat ligh innuence
C. Moderate mowerio:
D. Somcthat low ientacrice
1. Vory low mhurnes
f. No inthuence

41. Wilhin the chideare facilty where I am cmploved, the person(s) I percerve as having the grewest inhuene wn the loods served for chidren's meals and snacks is.
A. the center dirceror
B. the lead teacher in evelt classrown
C. Wie chiluren's partats familues
D. he indivitual clutdren
B. Whe couk elet wichion shar
5. other:
6. I work alone in a family chid care lnome

42. Withn the ehildeare lacinly whare I am enployed, the person I percerve as having: the greatest influence on mutrion cducation curriculum is:
A. the center dircetor
B. Whe lead teacher in each clasaroum

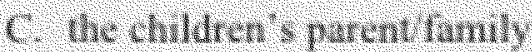
D. the individual tuldrn
E. the cook/chetkitchen stalf
F. other:
G. I work alone in a lamily chid carc home 
43. Within the childcare facility where I am employed, the person I perceive as having the greatest influence on the physical activity of the children is:
A. the center director
B. the lead teacher in each classtoom
C. the children's parent family
D. the individual children
E. the cook chetkitchen staf
F. other:
G. I work alone in a family child care home

44. A chald's developmental domains are listed below. Please rank each domain, based on the emphasis that you believe the staff at the childeare facility where you are cmployed places on that domain, with" "I" being the greatest emphasis and "3" being the least eniphasis.

A. cognitive intellectual domain

B. social enotional domain

C. physical domain

45. My gender is:
A. Female
B. Male

46. My race is:
A. White Caucasian
B. Black African-American
C. Native American
D. Asian or Pacific Islander
E. Hispanic
F. Othes

47. The highest level of education I have conpleted is:
A. GED or High School Diploma
B. Some college-level coursework
C. Associate's Degree
D. Bachelor's Degree
E. Master's Degree
F. Post-Master's Degree 
48. My total annual (yearly) household income is:
A. $\$ 10,000$ or lexs
G. $\$ 61,000 \cdot 570,000$
B. $\$ 11,000-\$ 20,000$
11. $571.000-\$ 80,000$
C. $\$ 21,000-\$ 30,000$
D. $\$ 31,000-540.000$
E. $\$ 41,000-\$ 50,000$
1. $\$ 81,000-590,000$
J. $\$ 91,000-\$ 100,000$
K. $\$ 100,000$ :
F. $\$ 51,000-\$ 60,000$

49. My birth date is

$$
\text { month day year }
$$

50. The location of the community college where I am completing this survey is:
A. Asheville-Buncombe Technical Community College
B. Blue Ridge Community College
C. Haywond Conmunity College
D. Southwestern Community College
E. Tri-County Community College 
APPENDIX FIVE 


\begin{tabular}{|c|c|c|c|c|c|c|}
\hline \multicolumn{6}{|c|}{ Caregiver's Feeding Styles Questionnaire } & \\
\hline & $\begin{array}{l}\text { These questions deal with YOUR interactions with your } \\
\text { preschool child during the dinner meal. Circte the best } \\
\text { answer that describes how often these things happen. If } \\
\text { you are not centain, make your best guess. } \\
\text { How often during the dinner meal do YoU... }\end{array}$ & Never & Marely & $\begin{array}{l}\text { Some } \\
\text { times }\end{array}$ & $\begin{array}{l}\text { Most } \\
\text { of the } \\
\text { Time }\end{array}$ & Always \\
\hline 1. & $\begin{array}{l}\text { Physically struggle with the child to get him or } \\
\text { her to eat (for example, physically putting the } \\
\text { child in the chair so he or she will eat). }\end{array}$ & 1 & 2 & 3 & 4 & 5 \\
\hline 2. & $\begin{array}{l}\text { Promise the child something other than food if he } \\
\text { or she eats (for example, "If you eat your beans, } \\
\text { we can play ball after dinner"). }\end{array}$ & 1 & 2 & 3 & 4 & 5 \\
\hline 3. & $\begin{array}{l}\text { Encourage the child to eat by arranging the food } \\
\text { to make it more interesting (for example, making } \\
\text { smiley faces on the pancakes). }\end{array}$ & 1 & 2 & 3 & 4 & 5 \\
\hline 4. & $\begin{array}{l}\text { Ask the child questions about the food during } \\
\text { dinner. }\end{array}$ & 1 & 2 & 3 & 4 & 5 \\
\hline 5. & $\begin{array}{l}\text { Tell the child to eat at least a little bit of food on } \\
\text { his or her plate. }\end{array}$ & 1 & 2 & 3 & 4 & 5 \\
\hline 6. & $\begin{array}{l}\text { Reason with the child to get him or her to eat (for } \\
\text { example, "Mitk is good for your health because } \\
\text { it will make you strong"). }\end{array}$ & 1 & 2 & 3 & 4 & 5 \\
\hline 7. & $\begin{array}{l}\text { Say something to show your disapproval of the } \\
\text { child for not eating dinner. }\end{array}$ & 1 & 2 & 3 & 4 & 5 \\
\hline 8. & $\begin{array}{l}\text { Allow the child to choose the foods he or she } \\
\text { wants to eat for dinner from foods already } \\
\text { prepared. }\end{array}$ & 1 & 2 & 3 & 4 & 5 \\
\hline 9. & $\begin{array}{l}\text { Compliment the child for eating food } \\
\text { (for example, "What a good boy! You"re eating } \\
\text { your beans"). }\end{array}$ & 1 & 2 & 3 & 4 & 5 \\
\hline 10. & $\begin{array}{l}\text { Suggest to the child that he or she eats dinner, for } \\
\text { example by saying. "Your dinner is getting cold". }\end{array}$ & 1 & 2 & 3 & 4 & 5 \\
\hline 11. & Say to the child "Hurry up and eat your food". & 1 & 2 & 3 & 4 & 5 \\
\hline
\end{tabular}




\begin{tabular}{|c|c|c|c|c|c|c|}
\hline 12. & $\begin{array}{l}\text { Warn the child that you will take away something } \\
\text { other than food if he or she doesn't eat (for } \\
\text { example, "If you don't finish your meat, there } \\
\text { will be no play time after dimer"). }\end{array}$ & 1 & 2 & 3 & 4 & 5 \\
\hline 13. & $\begin{array}{l}\text { Tell the child to eat something on the plate (for } \\
\text { example. "Eat your beans"). }\end{array}$ & 1 & 2 & 3 & 4 & 5 \\
\hline 14. & $\begin{array}{l}\text { Warn the child that you will take a food away if } \\
\text { the child doesn't eat (for example, "If you don't } \\
\text { tinish your vegetables, you won't get fruit"). }\end{array}$ & 1 & 2 & 3 & 4 & 5 \\
\hline 15. & $\begin{array}{l}\text { Say something positive about the food the child } \\
\text { is cating during dinner. }\end{array}$ & 1 & 2. & 3 & 4 & 5 \\
\hline 16 & $\begin{array}{l}\text { Spoon-feed the child to get him or her to eat } \\
\text { dinner. }\end{array}$ & 1 & 2 & 3 & 4 & 5 \\
\hline 17. & $\begin{array}{l}\text { Help the child to eat dinner (for example, cutting } \\
\text { the food into smaller pieces). }\end{array}$ & 1 & 2 & 3 & 4 & 5 \\
\hline 18. & $\begin{array}{l}\text { Encourage the child to eat something by using } \\
\text { food as a reward (for example, "If you finish your } \\
\text { vegetables, you will get some fruit"). }\end{array}$ & 1 & 2 & 3 & 4 & 5 \\
\hline 19. & Beg the child to eat dinner. & 1 & 2 & 3 & 4 & 5 \\
\hline
\end{tabular}

